\author{
SERIES "THORACIC IMAGING" \\ Edited by P.A. Gevenois and A. Bankier \\ Number 1 in this Series
}

\title{
Imaging guided thoracic interventions
}

\author{
B. Ghaye, R.F. Dondelinger
}

\begin{abstract}
Imaging guided thoracic interventions. B. Ghaye, R.F. Dondelinger. (C) ERS Journals Ltd 2001 .

ABSTRACT: Interventional Radiology is a technique based medical specialty, using all available imaging modalities (fluoroscopy, ultrasound, computed tomography, magnetic resonance, angiography) for guidance of interventional techniques for diagnostic or therapeutic purposes.

Actual, percutaneous transthoracic needle biopsy includes core needle biopsy besides fine needle aspiration. Any pleural, pulmonary or mediastinal fluid or gas collection is amenable to percutaneous pulmonary catheter drainage.

Treatment of haemoptysis of the bronchial artery or pulmonary artery origin, transcatheter embolization of pulmonary arteriovenous malformations and pseudoaneurysms, angioplasty and stenting of the superior vena caval system and percutaneous foreign body retrieval are well established routine procedures, precluding unnecessary surgery. These techniques are safe and effective in experienced hands.

Computed tomography is helpful in pre- and postoperative imaging of patients being considered for endobronchial stenting. Many procedures can be performed on an outpatient basis, thus increasing the cost-effectiveness of radiologically guided interventions in the thorax.
\end{abstract}

Eur Respir J 2001; 17: 507-528.

Dept of Medical Imaging, University Hospital Sart Tilman, Liège, Belgium.

Correspondence: B. Ghaye, Dept of Medical Imaging, University Hospital Sart Tilman B 35, B-4000 Liège, Belgium.

Fax: 3243667772

\section{Keywords: Arteries}

interventional radiology

stents

therapeutic blockade

thorax

transthoracic biopsy

Received: October 102000

Accepted after revision December 27 2000
Percutaneous nonoperative procedures in the chest were applied before the advent of imaging. LEYDEN [1] performed the first transthoracic needle lung biopsy in 1882 to confirm pulmonary infection. During the first half of the twentieth century, lung biopsy was mainly used to establish the microbiological diagnosis of extensive infectious lobar consolidation, which was easy to localize. Percutaneous needle sampling in the chest however, fell into disrepute, due to an unacceptable high rate of complications, caused by the large calibre of needles. Despite the use of smaller needles, pathologists remained reluctant to formulate a diagnosis on small samples or smears. Fluoroscopically guided bronchial brush biopsy was described in the sixties [2]. At the same time, the innovating work of NORDENSTRÖM and ZAJICEK [3] at the Karolinska Hospital in Stockholm popularized the technique of transthoracic fine needle sampling in the chest. The rate of pneumothorax was dramatically reduced with the systematic use of small gauge needles, although the rate of inadequate cellular material or false negative diagnoses in the confirmation of malignancy persisted in the $15-25 \%$ range. False positive diagnoses did not exceed $2 \%$. Transthoracic needle biopsy of mediastinal lymph nodes was described by a transjugular, a paraxiphoid or a paravertebral approach $[4,5]$. These transthoracic approaches were adopted on a routine basis, when computed tomography (CT) became available. Mediastinoscopy was also developed at the Karolinska Hospital, follo- wing the description of "artificial pneumomediastinum" [6]. A rigid cystoscope was introduced by Nordenström in the mediastinum under combined fluoroscopic and direct vision control (Nordenström, Karolinska Hospital, Stockholm, Sweden; personal communication). Percutaneous mediastinal puncture however, was not widely carried out before the advent of CT with reduced scanning times. Percutaneous insertion of drainage catheters in fluid collections of the pleura, lung or mediastinum, guided by fluoroscopy or CT was introduced in the late seventies using basic catheterguidewire techniques, which were applied already in the abdomen [7]. Arteriography of the bronchial arteries was also described in Sweden in the sixties. Chemoinfusion in bronchomediastinal arteries for treatment of inoperable bronchial carcinoma was the first clinical application of vascular interventional techniques in the chest, but was not widely spread [8]. Catheter embolization of bronchial or systemic arteries for treatment of haemoptysis was introduced in the next decade [9]. Miniaturization of catheters and refinement in embolic agents definitely established bronchial artery embolization as an accepted technique. Similar vascular occlusion techniques were applied in pulmonary arteries, first for treatment of haemoptysis, then as a means of occlusion of pulmonary arteriovenous fistula, with coils or detachable balloons $[10,11]$.

When adequate vascular catheters, wires and other devices, such as snare loops became available, 
percutaneous foreign body retrieval from the heart or pulmonary arteries became applicable [12]. The introduction of expandable metal vascular stents further broadened the spectrum of closed minimally invasive techniques in the chest, allowing for minimally invasive treatment of superior vena cava (SVC) obstruction with an immediate clinical result [13]. The most prominent interventional radiological techniques in the chest mentioned earlier will be discussed in this paper.

\section{Percutaneous nonvascular interventions}

The various percutaneous nonvascular applications that are in clinical use in the authors' department are listed in table 1 .

\section{Imaging guidance modalities}

Imaging techniques used for the guidance of interventional procedures include fluoroscopy and crosssection imaging or a combination of both [14]. A comparison of the different imaging modalities for percutaneous biopsy or drainage of thoracic lesions is given in table 2 .

\section{Fluoroscopy}

Uni- or bi-planar fluoroscopy was the first technique to be used as a guidance of percutaneous transthoracic needle biopsy (TNB) and drainage of fluid collections [3, 16-27]. Advantages are familiarity to most operators, real-time control of the procedure, and its wide

Table 1. - Percutaneous imaging guided nonvascular interventions in the thorax

\begin{tabular}{l} 
Frequent \\
Fine needle biopsy or fluid aspiration in the lung, pleura \\
and mediastinum \\
Catheter drainage of pleural, lung or mediastinal fluid or \\
air collections \\
Infrequent \\
Pre-operative localization of a lung nodule \\
Drainage of tension mediastinum \\
Percutaneous block of the upper sympathetic chain \\
Brachytherapy, electrochemical or radiofrequency treat- \\
ment of pulmonary malignancy* \\
Treatment of secondary pulmonary aspergilloma* \\
\hline
\end{tabular}

*: No personal experience. availability in radiological departments. Fluoroscopy allows adjustment of the tip of a catheter previously inserted into a fluid collection with ultrasonography (US) or CT control [28]. Opacification of fistulous tracts is best documented with fluoroscopy and plain films, in some occasions in combination with CT.

\section{Computed tomography}

CT offers exquisite anatomical display of all the thoracic structures and allows percutaneous access to all spaces with equal ease [14, 19-23, 28-33]. Intravenous contrast medium injection is mandatory for identification of necrosis, fluid content, normal vascular structures and false aneurysm located in an abscess wall, and also contributes to a precise delineation of a lesion with regard to the anatomical environment. CT is particularly useful for guiding puncture of a mediastinal lesion and an intrapulmonary lesion that is difficult to localize with fluoroscopy alone [29, 34]. CT allows for determination of an optimal cutaneous entry point in such a way as to avoid transgression of a pleural fissure or puncture of large vessels, bronchi and the oesophagus. The spiral scanning capability was not proved superior to sequential scanning [35]. Real time CT (fluoro-CT or continuous CT) is now widely available and combines the advantages of cross-section imaging and real time control of the procedure [36, 37].

\section{Ultrasonography}

Apart from it being the primary imaging guidance for biopsies of the chest wall or pleural lesions as well as lesions located in the anterior mediastinum [38, 39], ultrasonography (US) is particularly indicated to guide bedside percutaneous aspiration and catheter drainage of a pleural or pericardial fluid collection, even of only small amounts [19-22, 28, 40-43]. A subpleural pulmonary effusion and some pulmonary lesions with a parietal contact can also be punctured with US control [44-47]. The percutaneous approach is performed in the patient's position that optimally displays access to the lesion.

\section{Magnetic resonance}

Guidance of percutaneous interventions is a promising application of magnetic resonance (MR) [48, 49]. Little clinical experience is gained so far in thoracic interventions.

Table 2. - Comparison of imaging techniques for guidance of thoracic interventions

\begin{tabular}{lccccccc}
\hline Modality & Cost & Availability & $\begin{array}{c}\text { Radiation } \\
\text { (patient/physician) }\end{array}$ & $\begin{array}{c}\text { Length of } \\
\text { procedure }\end{array}$ & $\begin{array}{c}\text { Access to } \\
\text { central lesion }\end{array}$ & $\begin{array}{c}\text { Real time } \\
\text { control }\end{array}$ & $\begin{array}{c}\text { Mobilization of } \\
\text { the patient }\end{array}$ \\
\hline Fluoroscopy & + & +++ & $+/+$ & + & + & +++ & +++ \\
CT & ++ & ++ & $++/ 0$ & +++ & +++ & 0 & + \\
Fluoro-CT & ++ & ++ & $++/+$ & ++ & +++ & ++ & + \\
Ultrasonography & + & +++ & $0 / 0$ & ++ & 0 & +++ & +++ \\
MR & +++ & + & $0 / 0$ & +++ & +++ & + & + \\
\hline
\end{tabular}

Modified from KLEIN and ZARKA [15]. CT: computed tomography; MR: magnetic resonance. The plus symbols represent a qualitative assessment; the greater the number of plusses the greater the parameter. 


\section{Transthoracic needle biopsy}

In general, percutaneous tissue sampling of a pulmonary, pleural, or mediastinal lesion is performed when histological diagnosis will modify staging of the disease, influence therapeutic strategy, and when the diagnosis cannot be established by bronchoscopic techniques. TNB can be used as a less invasive alternative to mediastinoscopy in some mediastinal lesions as well as medical thoracoscopy in pleural pathologies.

\section{Indications}

Main indications for TNB are [14]: indeterminate thoracic nodule or mass; pulmonary nodule suggestive of malignancy, surgery being postponed after chemo- therapy and/or radiotherapy or replaced by these treatments; nodule in a patient with a clinical history of extrapulmonary primary malignancy, the patient being in clinical remission or presenting multiple primary malignancies; residual nodule following radiotherapy or chemotherapy; tissue sampling for therapeutic sensitivity tests, measurements of tumour markers, hormonal dependence, deoxyribonucleic acid (DNA) analysis, etc; chronic diffuse pulmonary infiltrate and evaluation of suspected focal infectious disease in normal or immunocompromised patients. The need for preoperative diagnosis of a solitary pulmonary nodule varies between institutions, and depends on the pretest probability of diagnosing a lesion that would obviate an unnecessary surgical thoracoscopy or thoracotomy [15]. The technique is faster, better tolerated and less expensive than surgery. Percutaneous puncture could also be indicated in
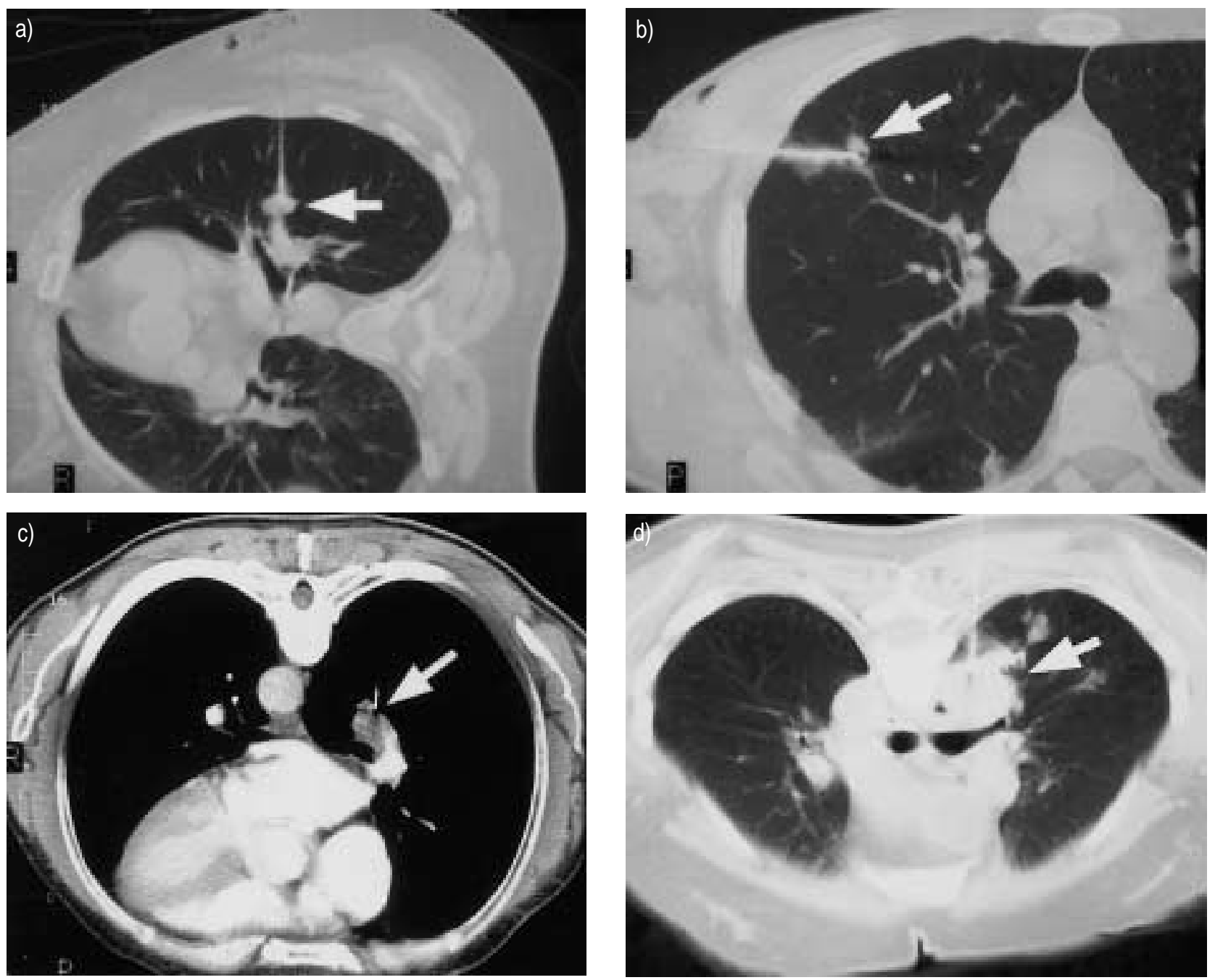

Fig. 1. - Percutaneous transthoracic needle biopsy. a) $11 \mathrm{~mm}$ left parahilar nodule (arrow) in a 65 -yr-old female. The procedure is performed in right lateral decubitus with a $20 \mathrm{G}$ aspiration needle. Pathology revealed neuroendocrine tumour, confirmed by subsequent surgery. b) 70-yr-old male presenting with a recent history of hepatocellular carcinoma and a past history of melanoma. Transthoracic needle biopsy (TNB) of a $7 \mathrm{~mm}$ nodule located in the right upper lobe (arrow) showed metastasis of melanoma. c) $20 \mathrm{~mm}$ right hilar mass (arrow) in a 53-yr-old male. Bronchoscopy was unremarkable. TNB performed during contrast medium injection to avoid vascular injury showed small cell lung carcinoma. d) Asymptomatic 45-yr-old female working in a microbiology dept, and presenting with a $35 \mathrm{~mm}$ mass (arrow) located in the right upper lobe. Bronchoscopy, bronchial biopsy and bronchoalveolar lavage were negative. TNB demonstrated positive culture for Mycobacterium tuberculosis. 

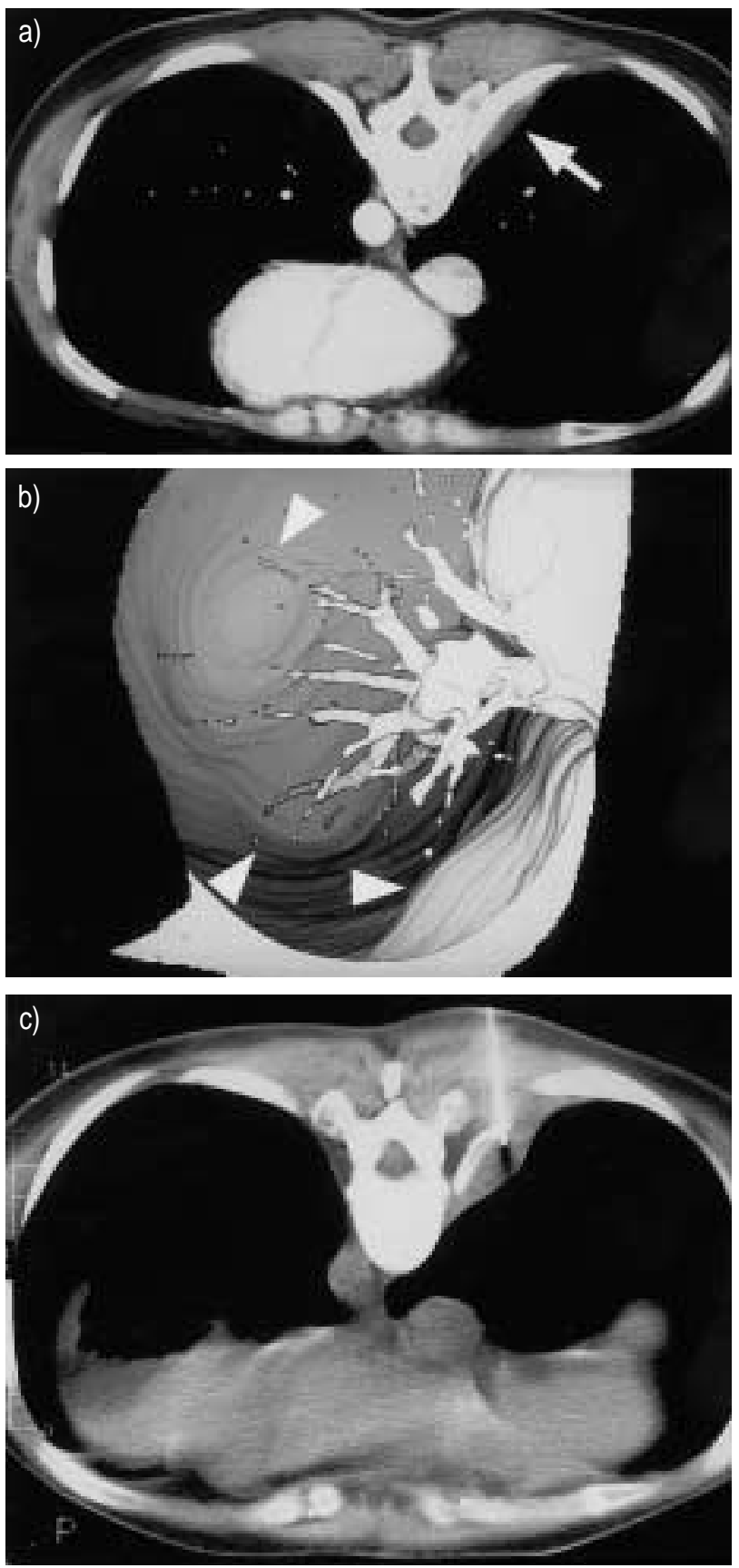

Fig. 2. - Percutaneous transthoracic pleural biopsy. Right pleural masses in a 33-yr-old female with a past history of invasive lympho-epithelial thymoma treated by surgery and radiation therapy 3 yrs earlier. a) Axial computed tomography (CT) slices demonstrate mild right pleural thickening (arrow) in contact with the 9th vertebral body and rib. b) Three-dimensional reconstruction (surface-shaded display) shows an endopleural view of the pleural surface with a posterior bulging corresponding to the findings of the native scan. Note also two pleural masses located along the diaphragm (arrowheads). c) Transthoracic needle biopsy (TNB) of the posterior pleural thickening confirmed recurrent thymoma.

localization of a lung nodule with a wire or a hook, or pleural tagging prior to video-assisted thoracic surgery (VATS) [50-53]. All mediastinal compartments are accessible to TNB, which is a useful alternative or add- on to mediastinoscopy or mediastinotomy for cytologic or histologic diagnosis of a hilar or mediastinal mass and for staging of lung cancer.

\section{Contra-indications}

There is virtually no absolute contra-indication to TNB [14, 54]. A vascular structure, hydatid cyst, meningocele or mediastinal pheochromocytoma is usually correctly diagnosed with imaging and/or laboratory tests. Coagulation disturbances should be recognized and corrected before sampling. Puncture of only one functional lung, chronic respiratory insufficiency, pulmonary arterial hypertension, cardiac insufficiency and severe emphysema are relative contraindications that may increase the complication rate of TNB or render any complication more significant. Dyspnoea or intractable cough or any other inability of the patient to cooperate may be overcome by the use of real time guidance techniques, such as fluoroscopy, US, or fluoro-CT and, if possible, appropriate medication.

\section{Results}

TNB has an accuracy varying $80-95 \%$ in the confirmation of pulmonary malignancy or malignant mediastinal adenopathy $[14,29,34,55-63]$. The negative predictive value of pulmonary biopsy is $84-96 \%$ and false positive results are noted in $2-4 \%[3,64]$. The diagnostic accuracy for small nodules with a diameter of $<2 \mathrm{~cm}$ is similar to that of larger lesions in experienced hands [65, 66] (fig. 1). A large number of cutting or aspiration needles, including automatic guns, with a needle calibre of $<1 \mathrm{~mm}$ and a variable tip design are currently used. Almost all needles allow cytological and histological sampling and give similar rates of results and complications concerning diagnosis of malignant or infectious disease. A specific benign diagnosis is more frequently established using a core biopsy needle than on aspiration of clusters of cells (44-100\% versus 12-47\%) [67-74]. Cutting needle biopsy also provides sufficient diagnostic material in patients with mediastinal lymphoma to guide therapy in $81-95 \%$ of patients, as well as in diffuse pleural thickening [15, 67, 75-79] (fig. 2). If the sampled material is inadequate or insufficient, but there is a cytologic or clinical suspicion of malignancy, biopsy should be repeated.

\section{Complications}

The most common complications of TNB are pneumothorax and haemoptysis. The incidence of pneumothorax varies $8-60 \%$, with a mean of $20 \%$. Less than $5 \%$ of patients have persistent clinical symptoms and require aspiration or drainage [14, 18, 19, 25]. Factors influencing pneumothorax are: chronic obstructive pulmonary disease, especially emphysema, age, poor patient collaboration, experience of the operator, duration of the procedure, number of transpleural 
needle passes, diameter and flexibility of the needle, depth and diameter of the target, difficulty of localization, cavitary lesion, and mechanical ventilation. Preoperative recognition of risk factors may lead to their correction, by administration of antitussives or bronchodilatators [54], or to the use of more sophisticated techniques, such as a co-axial needle technique, using a larger needle as a guide. In all cases, transgression of the needle through bullae should be avoided and the needle path through the normal lung should be kept to a minimum [80, 81] (fig. 3). Haemorrhage, with or without haemoptysis, is encountered in $<10 \%$ of TNB, most of which are self-limited [14, 55, 64]. Other complications, such as malignant seeding along the needle tract or air embolism, have become exceptional observations since the introduction of fine needle biopsy $[82,83]$. TNB related death rate is estimated at $0.02 \%[55]$.
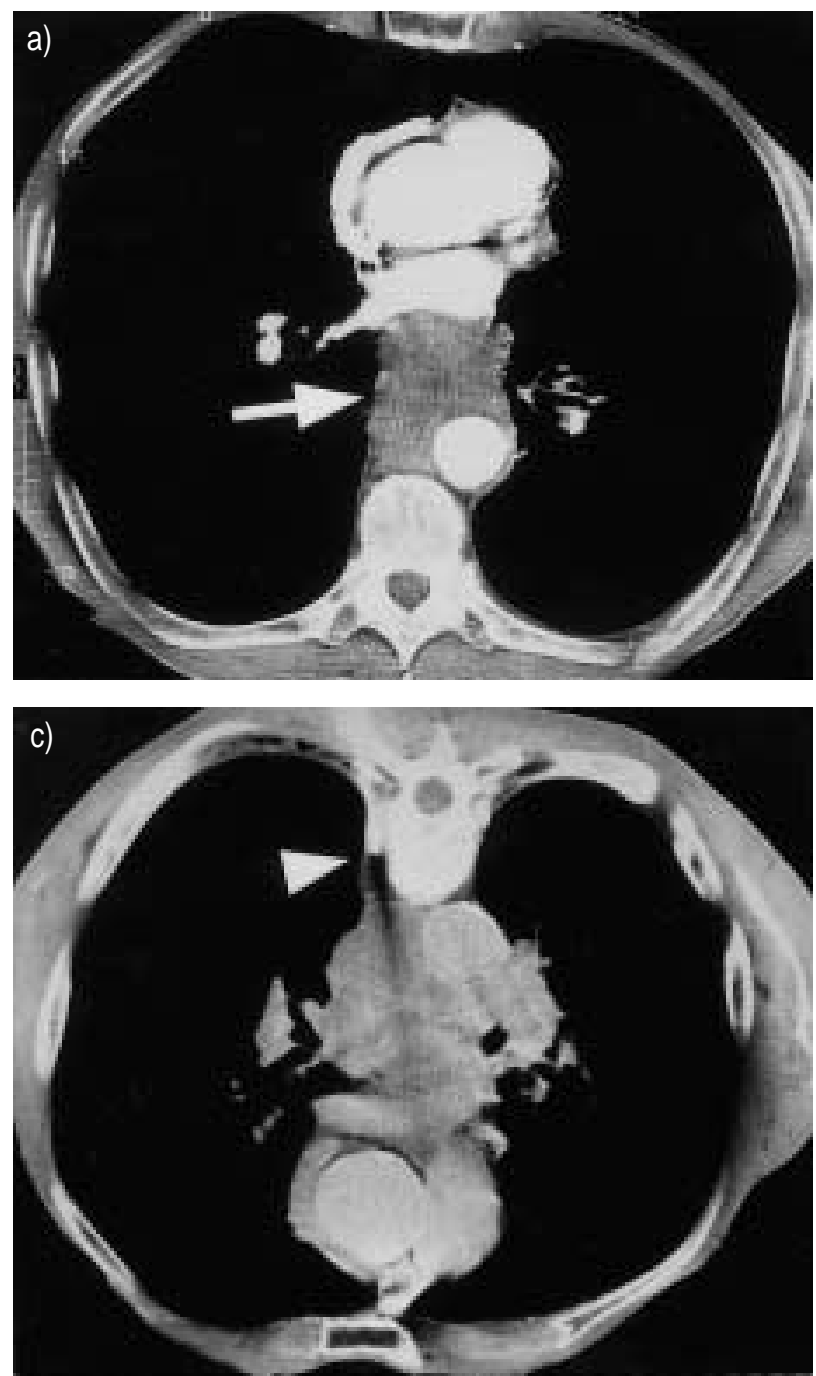

Clinical usefulness and cost-effectiveness of transthoracic needle biopsy

A comparison of different diagnostic techniques of lung lesions is given in table 3 . A recent study on the influence of TNB on treatment showed that management was altered in $51 \%$ of patients and unaltered, i.e. confirmed the diagnosis of a resectable malignancy or provided nondiagnostic results in $49 \%$. Surgery was avoided in $83 \%$ of biopsies that altered patient treatment [84]. When the pretest likelihood of malignancy of a resectable lesion is high, proceeding directly to thoracotomy is appropriate since preoperative TNB is unlikely to alter patient management [15]. Otherwise, TNB and fiberoptic bronchoscopy (FOB) must be considered complementary and TNB performed only after a negative FOB. In indeterminate pulmonary nodules, VATS may be the method of
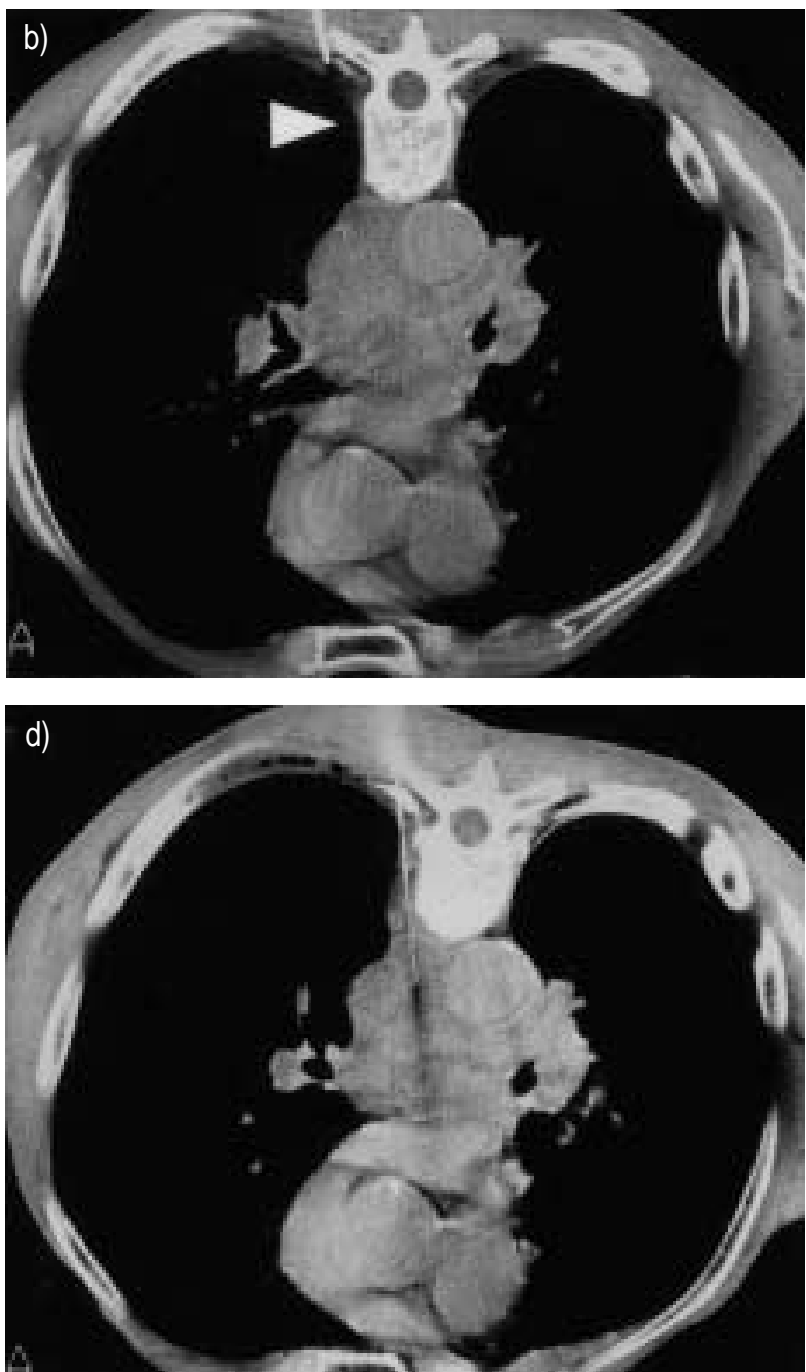

Fig. 3. - Artificial widening of the extrapleural space for safe transthoracic needle biopsy (TNB) of mediastinal lesion by an extrapleural approach. A 66-yr-old male presented with dysphagia and altered general condition for since 6 months. Chest radiography showed a middle mediastinal mass. a) Computed tomography (CT) confirms a large mediastinal subcarenal soft tissue mass (arrow). Flexible fibroscopy was unremarkable. Transcarinal needle biopsies were negative. b) CT guided TNB was performed in a prone position. Absence of extrapleural fat prohibits a safe mediastinal access (arrowhead). c) Widening of the extrapleural space was obtained by injection of $50 \mathrm{~mL}$ of saline (arrowhead), which displaces the pleura laterally. d) Using a coaxial technique, a small cutting needle was advanced into the lesion through a larger outer needle. Pathology showed poorly differentiated adenocarcinoma. 
Table 3. - Comparison of different diagnostic modalities of pulmonary lesions

\begin{tabular}{lccccc}
\hline Technique & Availability & $\begin{array}{c}\text { Total cost including } \\
\text { hospital stay N }\end{array}$ & $\begin{array}{c}\text { Diagnostic } \\
\text { accuracy } \%\end{array}$ & Pneumothorax \% & Diagnosis and treatment \\
\hline Bronchoscopy & +++ & 1 & $30-90$ & $1-3$ & + \\
TNB & +++ & $1-2$ & $80-95$ & $8-60$ & - \\
VATS & ++ & $20-30$ & $\geqslant 95$ & 100 & yes \\
Thoracotomy & +++ & $40-80$ & $\sim 100$ & 100 & yes \\
\hline
\end{tabular}

TNB: transthoracic needle biopsy; VATS: video-assisted thoracic surgery; N: mean cost of bronchoscopy. The plus symbols represent a qualitative assessment, the greater the number of plusses the greater the parameter.

choice, providing simultaneous diagnosis and treatment and reducing total cost (table 3 ).

\section{Percutaneous drainage of thoracic fluid collections}

Image guided percutaneous aspiration or drainage of fluid (or air) collection is considered a valid alternative to surgery. Increased safety and effectiveness compared to blind techniques have been largely demonstrated. Any collection located in the pleural space, pericardium, lung or mediastinum can be aspirated or drained percutaneously with catheter placement under imaging guidance.

\section{Pleural collections}

Pleural effusions, including empyema, haemothorax, chylothorax and pneumothorax can be considered for percutaneous closed catheter drainage.

Empyema. Indications for catheter drainage depend on the evolutionary stage of the pleural effusion, according to the classification of LiGHT [85-87]. The early stage (exsudative phase) corresponds to the secretion of a protein rich fluid by the pleura. This is a mandatory transitional phase for empyemas and does not require drainage. The second stage (fibrinopurulent phase) is characterized by a viscous and opaque fluid with increased cellularity. Deposition of fibrin layers on the pleural surface promotes the formation of pleural pockets and progressive lung entrapment. Medical treatment without effective fluid drainage might fail. The third stage (organizing phase) is characterized by fibroblastic infiltration of the pleura, limiting the expansion of the underlying lung due to pleural peels. Early drainage of a complicated effusion is necessary to prevent progression to the organized phase, which requires surgical decortication. In surgical treatment, blind placement of a thoracostomy tube $(30 \mathrm{~F}-34 \mathrm{~F})$ is followed by open surgical drainage if unsuccessful, although some surgeons recommend early open drainage, and pleural decortication, as the initial therapeutic approach $[85,88]$.

Imaging guided percutaneous drainage avoids the potential failures associated with blind chest tube placement, which can occur in about $50 \%$ of patients due to inadequate positioning of the tube or to undrained satellite pleural pockets $[86,87]$. The size of the percutaneous catheters that are in regular use varies from $7 \mathrm{~F}-30 \mathrm{~F}$ and is chosen according to the viscosity of the fluid to be drained. CT discloses all satellite noncommunicating pleural pockets, that are drained with multiple catheters. Pleural fluid, which is encapsulated in a fissure can also be adequately drained with CT control, most often without transgression of normal lung by the catheter. Technical success is achieved in almost all cases. Clinical success is achieved in $70-89 \%$ of the patients treated in a first intent, depending on the stage of empyema $[14,17,20-22,25$, $27,28,31,32,41,42]$. A similar success rate of $80 \%$ is obtained in patients treated in a second intent following failed surgical chest tube drainage $[14,17,21-23,27$, 28]. Failure of percutaneous drainage varies $11-30 \%$, and usually occurs in chronic empyema (stage III), when extensive pleural peels have formed, which may prevent catheter insertion, or the cavity to collapse and obliterate. CT may have its difficulties to accurately differentiate between the fibrinopurulent and organizing phase of empyema [89]. Medium sized catheters are better tolerated by the patient than large thoracostomy tubes, but their lumen is more prone to obstruction by fibrin products. Intrapleural injection of fibrinolytic agents was recently proven to be efficient in preventing fibrin deposit and formation of secondary loculation of the empyema, with a clinical success rate of $62-100 \%$ $[14,23,26,90-104]$. Local instillation of fibrinolytics also reduces the number of drainage catheters, that are necessary to drain all loculations, duration of drainage and hospitalization and prevents fibrosis of the pleural surface (fig. 4). Table 4 summarizes the basic principles and recommendations for successful treatment of complicated pleural empyema. Overall, the added cost of imaging guidance is largely compensated for by the savings from an increase in clinical success.

Malignant pleural effusion. Recurrent malignant pleural effusion, that is not controlled by systemic treatment, is usually drained with a soft and small catheter $(8 \mathrm{~F})$ followed by pleural sclerosis by intrapleural injection of talcum, doxycyclin, bleomycin or other drugs. Advantages of small catheters compared to classic large-bore thoracostomy tubes are the possibility of treatment on an outpatient basis and increased patient comfort. Advantages of imaging guidance is the proper insertion of the catheter inside the pleural cavity, thus avoiding injury of a pleural mass, which may bleed during catheter insertion, nonrecognition of persistent undrained loculations and uncomplete lung re-expansion before pleural sclerosis. Complete regression of a malignant pleural effusion is obtained in $53-81 \%$ and partial resolution in up to $95 \%$, which is a similar response rate than obtained with large thoracostomy tubes [24, 43, 105-107]. 



Fig. 4. - Percutaneous drainage of pleural collection. A 64-yr-old male with chronic obstructive pulmonary disease (COPD) presented with right multiloculated pleural collection, following surgical drainage of pneumothorax complicated by superinfected hemothorax. a) Contrast-enhanced spiral computed tomography (CT) section demonstrates a large multiloculated pleural collection. Areas of high densities (arrowheads) suggest presence of fresh clot. b) Aspiration with a Teflon-sheathed catheter confirms the presence of blood; a $24 \mathrm{~F}$ chest tube (arrow) was inserted in the dependant part of the collection. Cultures were positive for Escherichia coli. 200,000 IU of urokinase were injected per day for 5 days. c) Spiral CT control demonstrates regression of the collection and persistence of an intrafissural collection (arrow). Urokinase injection was continued for 3 more days before chest tube removal and discharge of the patient. Total drainage volume was $1200 \mathrm{~mL}$. Note on figures b) and c) 4 to $5 \mathrm{~mm}$ pleural thickening at the time of drainage. d) High-resolution computed tomography (HRCT) at $1 \mathrm{yr}$ demonstrates complete regression of pleural thickening, with subnormal expansion of the right lower lobe.

Haemothorax. Post-traumatic haemothorax is usually drained by large-bore surgical chest tubes. In selected cases with persistent intercostal or phrenic artery bleeding, angiography and transcatheter embolization is indicated before drainage. Long-lasting multiloculated haemothorax is an indication for image-guided catheter drainage. Fibrinolytic agents can be safely injected in a pleural haematoma at 1 week following trauma [97, 98] (fig. 4). Uncontrolled intrapleural bleeding is an absolute contra-indication of intrapleural fibrinolysis.

Pneumothorax. Postbiopsy or spontaneous pneumothorax can be drained percutaneously with a small calibre catheter (fig. 5). Success rate of drainage of iatrogenic pneumothorax is $75-97 \%$, the vast majority resolving within $24-72 \mathrm{~h}$ [18, 19, 25, 86, 107, 108]. Catheters can be connected to a one-way Heimlich valve. Recurrent pneumothorax can be treated with chemical pleurodesis if surgical therapy is not an option.

\section{Pulmonary collections}

Abscess. Pyogenic pulmonary abscesses rarely occur today, owing to progress in antibiotic treatment and a more efficient eradication of the cause. When resistant to medical treatment, postural and bronchoscopic drainage, lung abscess is amenable to percutaneous catheter drainage before considering surgery [14]. Abscesses frequently present with a large pleural contact, which allows percutaneous insertion of a $7 \mathrm{~F}-$ $14 \mathrm{~F}$ catheter without transgression of normal lung parenchyma (fig. 6). Resolution of the abscess is obtained in $73-100 \%$ following $10-15$ days of drainage [7, 30, 31, 33, 40, 109-113]. Pulmonary abscesses may have a thick wall and complete collapse of the cavity may take 4-5 weeks. Decompression should be performed slowly to avoid rupture of a vessel or a Rasmussen pseudoaneurysm incorporated in the abscess wall. Surgery remains necessary when extensive necrotizing pneumonia or life-threatening haemorrhage has occurred [14]. 
Table 4. - Basic principles of image guided drainage (modified from MOULTON) [87]

Reasons for failed blind-inserted chest tube

Malposition

Imaging guidance

Viscosity

Adapted size of the catheter or tube

Fibrin deposits

Fibrinolytic agents

Stage III pleural peels ( $>6$ weeks)

Decortication

Proper use of imaging guidance

Accurate assessment of the underlying pathology

Planning of drainage procedure

Evaluation of drainage outcome

Initial aggressive catheter management is the key point of success

Multiple loculations

Multiple catheters

Fibrinolytic agents

Use of intracavitary fibrinolytic agents

Allows complete evacuation of fibrinous fluid

Partially debride pleural surface

Facilitate re-expansion of the underlying lung

Should never be used in a possibly malpositioned chest tube
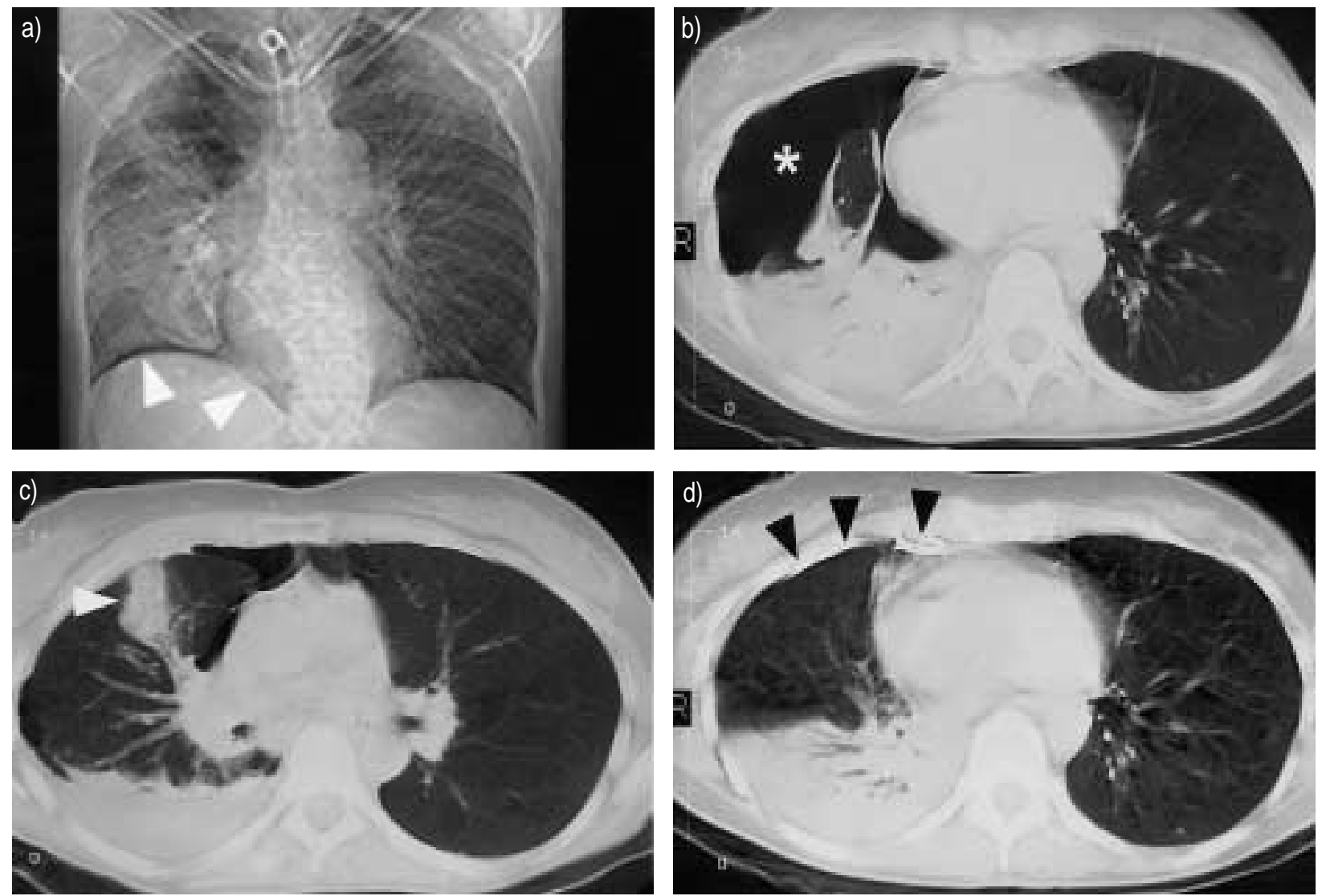

Fig. 5. - Percutaneous drainage of loculated pneumothorax. A 37-yr-old female with a past history of multiple sclerosis presented with severe dyspnoea and temperature. Chest radiography showed a right pneumothorax, pulmonary infection and large bullae in the right apex. a) Insertion of 3 large-bore chest tubes failed to resolve a pneumothorax located in an antero-inferior position (arrowheads). b) and c) Spiral computed tomography (CT) confirmed basal pneumothorax (star) and right lower lobe atelectasis with pleural effusion of limited volume. A previously blindly placed chest tube is located inside the lung parenchyma, and surrounded by areas of pulmonary hemorrhage (arrowhead). Laterally, adhesions have formed between the parietal and visceral pleura. d) A $9 \mathrm{~F}$ pigtail catheter (arrowheads) was inserted under CT guidance in the anterior costo-diaphragmatic sulcus and drained air and $200 \mathrm{~mL}$ of sterile fluid. Subsequent chemical pleurodesis was performed through the pleural catheter.
Aspergilloma. Life-threatening haemoptysis due to intracavitary aspergilloma may be recurrent, despite an initially successful bronchial embolization, and require surgical resection [114-120]. Open pulmonary condition $[118,120]$. Transthoracic instillation of amphothericin B has been described with cess rate of $50 \%$ for resolution of the aspergilloma and $75-100 \%$ for acute control of hae-

Pneumatocele and bulla. Percutaneous drainage of infected or tension pulmonary pneumatocele has been described $[14,122]$. A percutaneous diagnostic aspi-
ration with an 18-Gauge needle can precede catheter insertion in doubtful cases, as bullae may frequently contain an air fluid level, without infection.

\section{Mediastinal collections}

Abscess. Mediastinal abscesses are challenging to treat by a closed percutaneous approach, as overall some patients who present with a severe underlying 

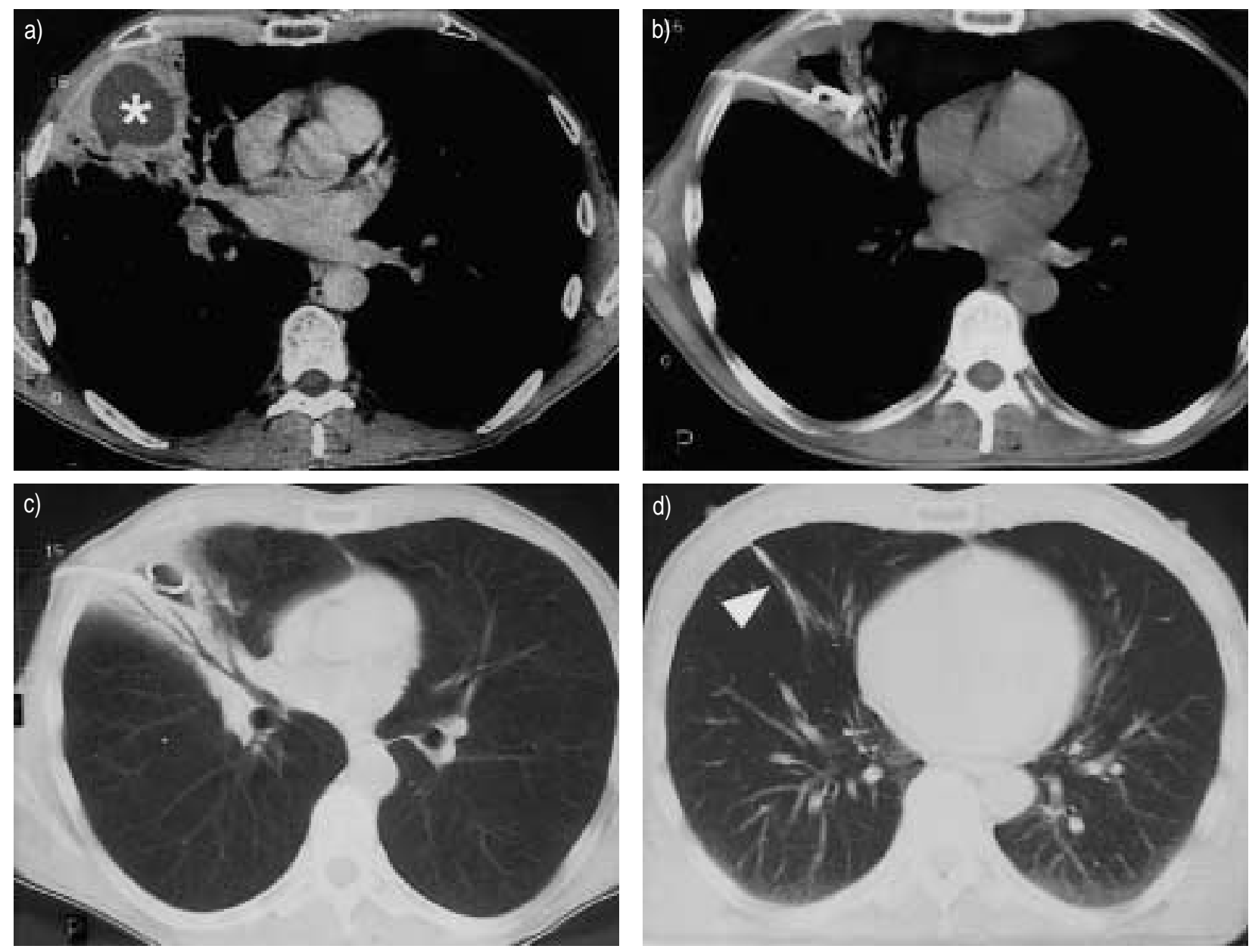

Fig. 6. - Percutaneous drainage of pulmonary abscess. A 55-yr-old male with a past history of hemilaryngectomy for squamous cell carcinoma and recurrent episodes of aspiration presented with elevated temperature and altered general condition. a) Contrast-enhanced computed tomography (CT) demonstrates a 5-cm pulmonary abscess (star) located in the right middle lobe. b) An 8F pigtail catheter was inserted in the abscess under CT guidance through the large thoracic wall contact of the abscess. Forty mL of pus were aspirated. Thirty $\mathrm{mL}$ were drained during the next 3 days. Cultures were negative. c) CT control on the third day showed partial collapse of the cavity, filled by air and surrounded by parenchymal consolidation. The catheter was removed. d) CT control obtained 3 months later showed complete disappearance of the lesions and a plate-like atelectasis (arrowhead).

prognosis of the patient is usually poor. Mediastinal collections can be drained under CT guidance using a parasternal catheter approach for collections located in the anterior mediastinum (fig. 7) and a posterior paraspinal approach for safe access to the posterior and middle mediastinal compartments [14, 27].

When a mediastinal abscess is associated with oesophageal perforation, an oesophageal catheter can be inserted in the mediastinum over a guide wire through the oesophageal tear [123]. The few reported series indicate a success rate of $83-100 \%$, but 30 days mortality is high, owing to the underlying disease [31, 123-125].

Pericardial effusion. Most pericardial effusions are drained under US control using a subcostal or a subxyphoid approach [126]. When US fails, fluid can be drained under CT guidance, by an atypical left anterolateral approach [127] (fig. 8).
Tension pneumomediastinum. Tension pneumomediastinum usually results from barotrauma in mechanically ventilated patients. A tension mediastinal emphysema may compress the large mediastinal veins and the heart, leading to pseudotamponade which urges for rapid decompression. The usual treatment is mediastinostomy. Percutaneous insertion of a $12 \mathrm{~F}$ or $14 \mathrm{~F}$ catheter with sideholes into a retrosternal mediastinal gas collection under CT guidance is an alternative emergency treatment [128].

Others. Ectopic pancreatic pseudocysts, pleuropericardial, parathyroid or bronchogenic cysts, necrotic tumours, lymphoceles and haematomas can be drained or aspirated percutaneously using imaging guidance [14].

\section{Vascular interventions}

Vascular interventions that are in clinical use are listed in table 5. 

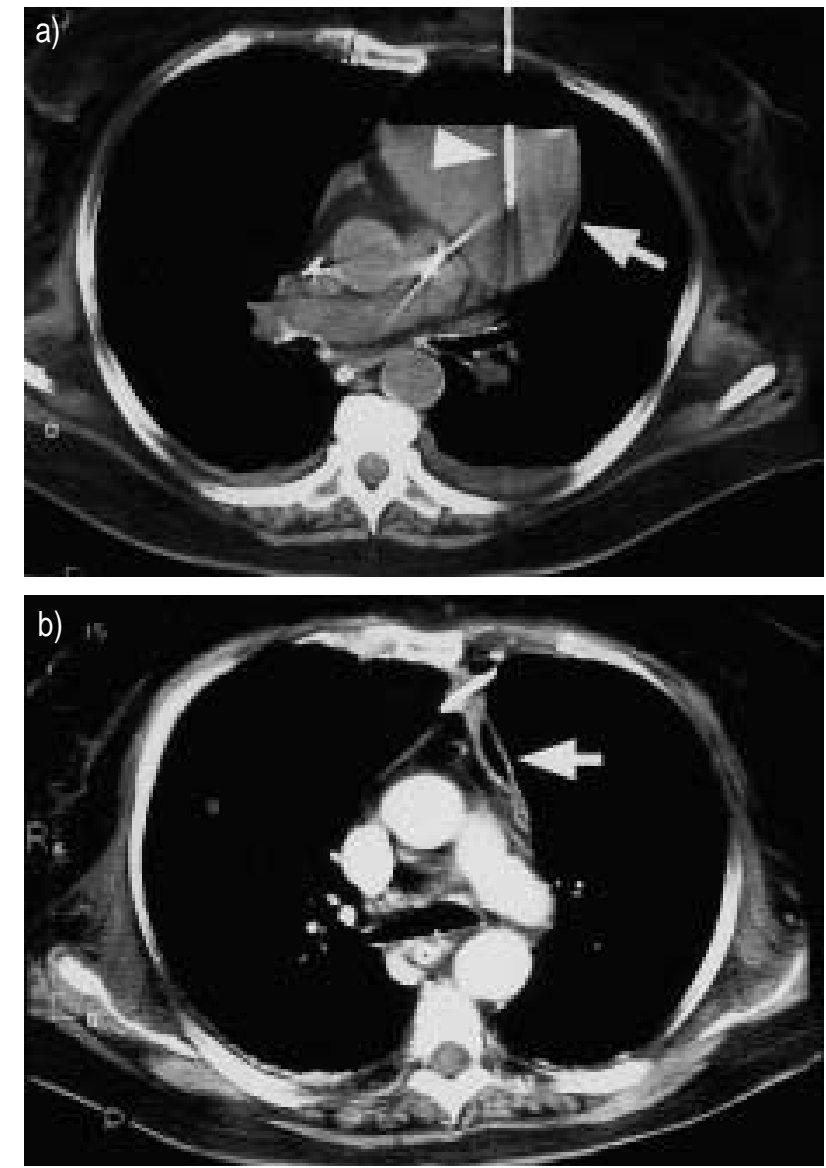

Fig. 7. - Percutaneous drainage of mediastinal collection. A 68yr-old female presented with epilepsy related to a frontal cerebral haematoma. Latrogenic bilateral pneumothorax and pneumomediastinum followed difficult intubation with laceration of the tracheal wall. Pneumothoraces were drained by surgical chest tubes; 2 days later, chest radiography showed a large mediastinal widening. a) Computed tomography (CT) demonstrates an extensive hydro-haemomediastinum located in the anterior mediastinum (arrow). A 9F pigtail catheter (arrowhead) was inserted under CT guidance, and drained $450 \mathrm{~mL}$ of bloody fluid in $48 \mathrm{~h}$. b) $\mathrm{CT}$ control at $48 \mathrm{~h}$ showed complete regression of the collection (arrow).

This section focuses on the treatment of haemoptysis, pulmonary arteriovenous malformation and pseudoaneurysm, superior vena cava obstruction and percutaneous retrieval of vascular foreign bodies.

\section{Bronchial artery embolization}

\section{Indications}

Haemoptysis can be classified as massive $(>300 \mathrm{~mL}$ in $2448 \mathrm{~h}$ ), moderate ( $\geqslant 3$ episodes of $>100 \mathrm{~mL}$ within a week) and chronic (quantitatively small episodes of haemoptysis repeated over the course of weeks or months). Massive haemoptysis carries a high mortality rate in patients treated conservatively, and many patients are unfit for lung resection. When surgery is performed in an acute situation, morbidity is high and a mortality rate of $35 \%$ has been reported [129-133]. Most frequent causes of bleeding include
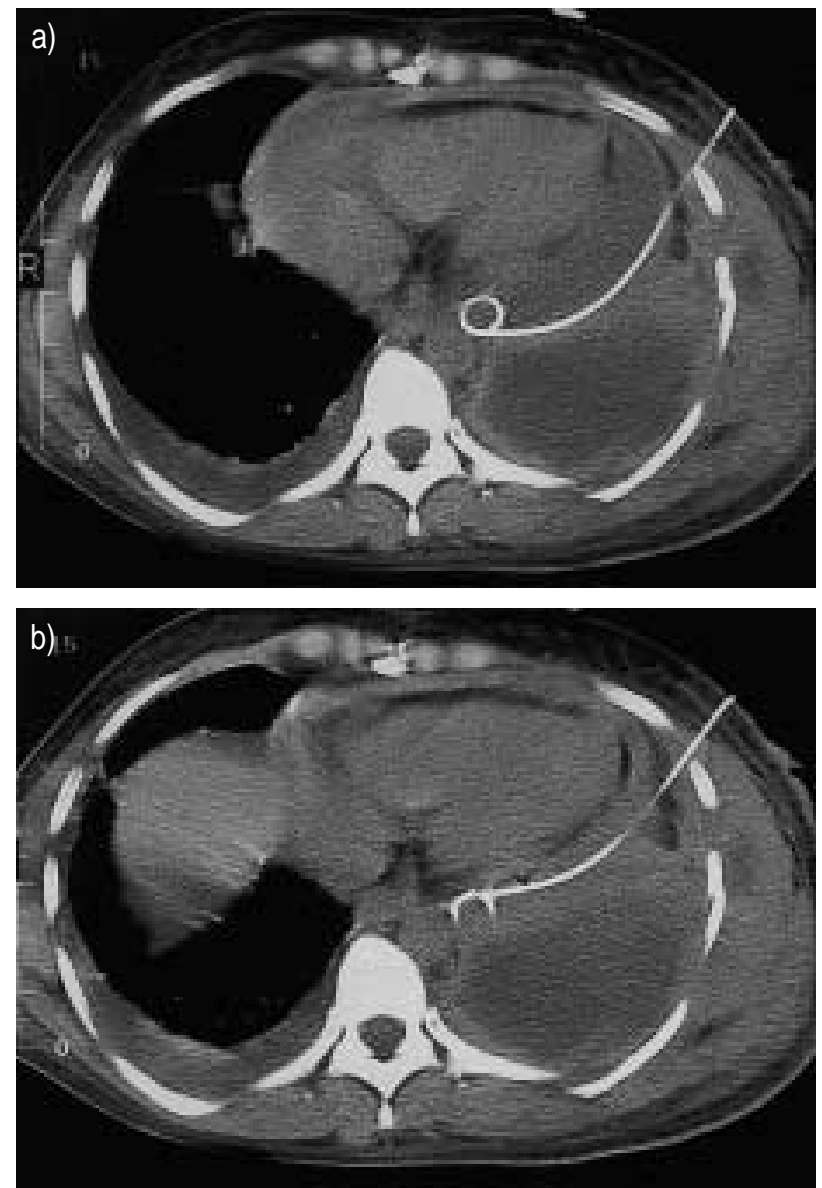

Fig. 8. - Percutaneous pericardial drainage. A 38-yr-old female presented with sudden dyspnoea following left pneumonectomy for tuberculosis complicated by aspergilloma, unresponsive to medical treatment. a) Echocardiography demonstrated cardiac tamponade, confirmed by computed tomography (CT) Percutaneous insertion of a $5 \mathrm{~F}$ catheter in the posterolateral part of the pericardial sac under CT guidance allowed aspiration of $410 \mathrm{~mL}$ of a sterile bloody effusion. b) Immediate CT control following catheter placement and aspiration showed almost complete regression of effusion and increase of volume of the heart chambers. The $5 \mathrm{~F}$ catheter was exchanged for an $8 \mathrm{~F}$ pigtail catheter to avoid clogging. The catheter was left in place for $72 \mathrm{~h}$ and drained $50 \mathrm{~mL}$ of blood. No recurrence.

tuberculosis, chronic infection, bronchiectasis, aspergilloma, pneumoconiosis, bronchogenic carcinoma, pulmonary metastasis and pulmonary infarction $[132$, 134-136]. Chest radiography and bronchoscopy should be obtained immediately to localize the site of bleeding. CT may be considered in noncritical patients to search for the underlying cause or determine the exact bleeding site whenever chest radiographs are inconclusive. In cases of massive haemoptysis requiring an urgent embolization, angiography is recommended as the initial intervention. Following embolization, surgery can be carried out in a second intent for localized disease [133]. In moderate or chronic haemoptysis, bronchial embolization is the only treatment, when unresponsive to medical treatment in the following situation: recurrent haemoptysis following surgery, postradiation lung, unresectable carcinoma, bilateral pulmonary disease, inadequate lung function to tolerate 
Table 5. - Vascular interventions in the thorax

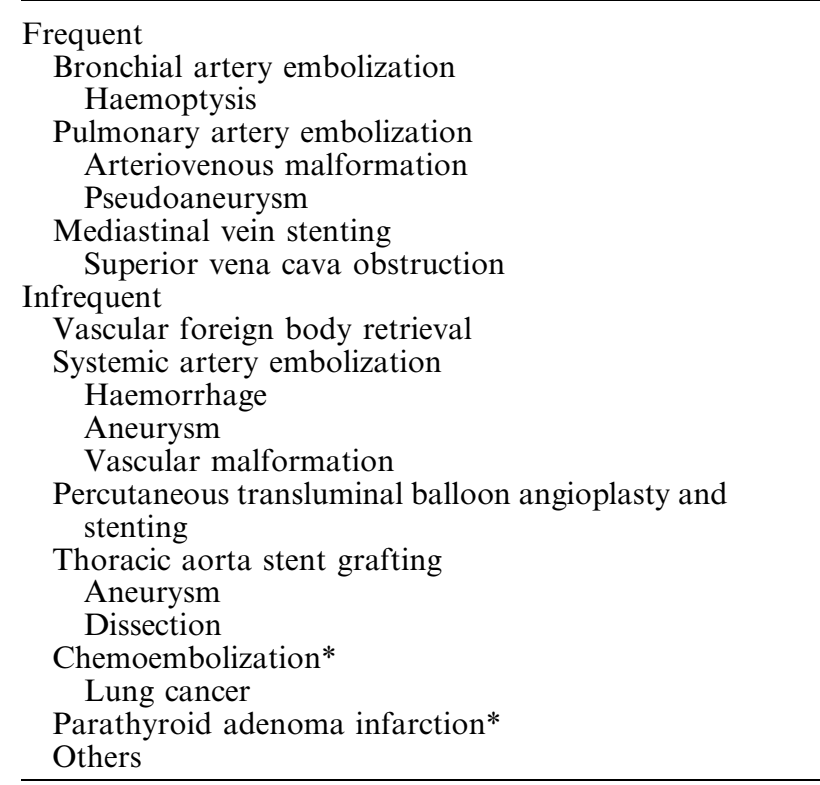

*: No personal experience.

resection, failure to localize a bleeding source roentgenographically and/or bronchoscopically, and large transpleural connections between bronchial and nonbronchial systemic arterial supply.

Technique. A thoracic aortogram is always obtained to map all bronchial arteries and systemic nonbronchial feeders of the bleeding site. Selective opacification of all bronchial arteries is then performed beginning with the vessels directed to the suspected bleeding area. Arteries with an increased calibre, and a tortuous course and parenchymal hypervascularity are found (fig. 9). Contrast extravasation in the lung parenchyma or in the bronchial lumen is not required to decide on embolization. Vaso-occlusion is best per-
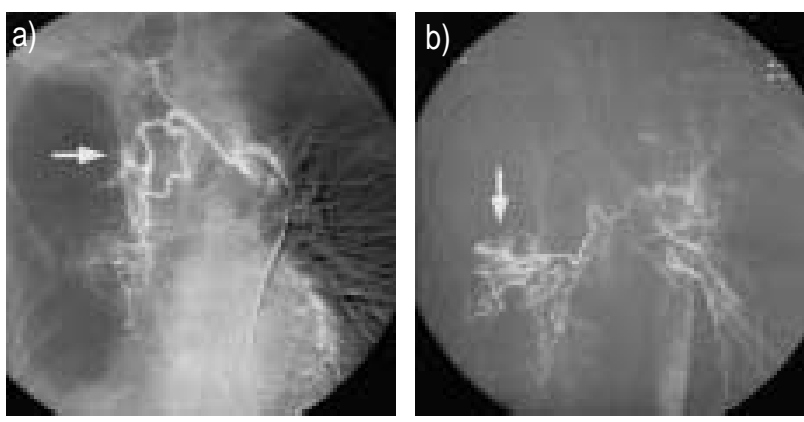

Fig. 9. - Embolization of bronchial arteries. A 71-yr-old male with a past history of pleuroparenchymal tuberculosis presented with chronic episodes of haemoptysis of small amount for 5 months. The patient underwent previous bronchial embolization for haemoptysis 11 yrs before. a) Arteriography of the right intercostobronchial trunk demonstrates an increased calibre and a tortuous course of the bronchial artery and areas of parenchymal hypervascularity (arrow). Embolization with polyvinyl alcohol particles was performed. b) Arteriography of a common right and a left bronchial arterial trunk showed other areas of abnormal hypervascularity fed by a dilated and tortuous right bronchial artery (arrow). Embolization with particles. formed through a microcatheter that is inserted coaxially through a diagnostic catheter, the tip of which is placed in the proximal portion of the vessel or at its ostium. Microcatheters, which can be placed selectively distal to the origin of a spinal artery are not occlusive and allow for optimal catheter stability and safety during embolization avoiding reflux of embolization material [136-138]. Polyvinyl alcohol particles, gelfoam and dextran microspheres are among the agents that are in frequent clinical use. Additional bronchial and nonbronchial collaterals (internal and external thoracic arteries, periscapular arteries, cervical arteries, intercostal arteries and inferior phrenic artery) are catheterized and may be treated, when their contribution to the hypervascular area is shown on angiography [132, 139, 140] (fig. 10). Nonbronchial systemic collaterals may resume the distal bronchial circulation after a previous bronchial embolization and be responsible for bleeding recurrence [141].

Results. In a review of the recent literature, bleeding (predominantly massive) was controlled in an acute setting in $75-90 \%$ of the patients [142]. Bleeding recurrence rate was $16-48 \%$. In one study with longterm outcome, the Kaplan-Meier curves showed 18\% of recurrences within 7 days, $24 \%$ within 1 month, $33 \%$ within 6 months and $38 \%$ within 1 yr. No further recurrences occurred 1-2 yrs after embolization [142]. Recurrence can be caused by incomplete bronchial embolization, recanalization of an embolized
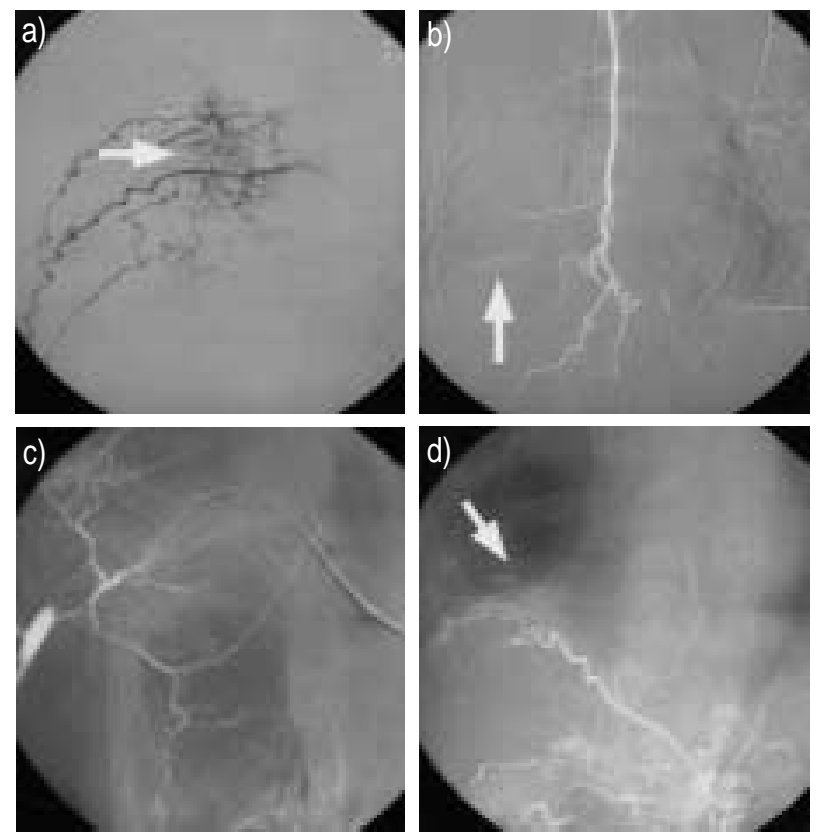

Fig. 10. - Embolization of systemic nonbronchial collaterals (same patient and same procedure as in fig. 9). a) Opacification of a dilated fourth right intercostal artery and adjacent metameric arteries, shows extensive pleural and parenchymal hypervascularization (arrow). Embolization with particles. b) Opacification of the right internal thoracic artery shows a small parenchymal blush in the lower part of the right hemithorax. No embolization is required. c) Opacification of periscapular and external thoracic arteries. Normal aspect. d) Opacification of the right inferior phrenic artery, showing limited basal pleuroparenchymal hypervascularization (arrow). No embolization. 
artery, development of extrapulmonary systemic collaterals (short-term recurrence), or by progression of the underlying disease (long-term recurrence) [136, 142]. Usually, recurrent haemoptysis responds to a second embolization procedure. Bleeding from a pulmonary artery should be suspected if the bronchial arteries are angiographically normal or if em bolization of the bronchial and nonbronchial arteries fails to stop the bleeding.

Complications. Complications are encountered in 1\% of the patients. A postembolization syndrome may be observed (pleuritic pain, fever, dysphagia, leukocytosis); it will last for 5-7 days and responds to symptomatic treatment [143]. Bronchial wall or oesophageal wall necrosis, inadvertent facial or abdominal visceral embolization, myocardial infarction and spinal cord infarction are rare complications that can be avoided by proper technique.

\section{Pulmonary artery embolization}

\section{Arteriovenous malformation}

Indications. Pulmonary arteriovenous malformations (PAVMs) are arteriovenous shunts which represent a potential source of paradoxical emboli through a right to left shunt, without altering pulmonary artery pressure or cardiac output. Other potential complications include systemic oxygen desaturation resulting in polycythaemia, and haemoptysis or haemothorax caused by rupture of the aneurysmal sac. Most PAVMs are congenital and multiple, being part of the hereditary haemorrhagic telangiectasia (RenduWeber-Osler) syndrome, while a minority are acquired, mainly secondary to vascular damage [136, 144-147]. They can be classified as simple (one segmental feeding artery: one draining vein) or complex (several segmental feeding arteries: one or several draining veins) [148, 149]. Before 1980, surgical lobectomy or pulmonary wedge resection was the only valid therapy. Selective embolization is at present considered the treatment of choice for PAVMs which show a feeding artery superior to $3 \mathrm{~mm}$ in diameter. In fact, large shunts are associated with an increased incidence of paradoxical emboli potentially causing severe neurological complications [146-153]. Multiple microscopic shunts are usually present in addition to the visible fistulae and small AVMs may increase in size during lifetime. Endoluminal embolization offers the advantage of a maximal preservation of normal lung parenchyma around the malformation, particularly in patients with multiple and bilateral PAVMs.

Technique. Pre-embolization thin section helical CT with 3D reconstruction of the PAVM is an important step in identifying all small feeding arteries, which may be responsible, when not recognized, of persistent shunting following embolization of the main feeder only [149]. Selective transcatheter embolization of all feeding arteries is performed with steel coils with attached cotton strands (fig. 11). All catheter and guidewire exchanges and coil introduction into
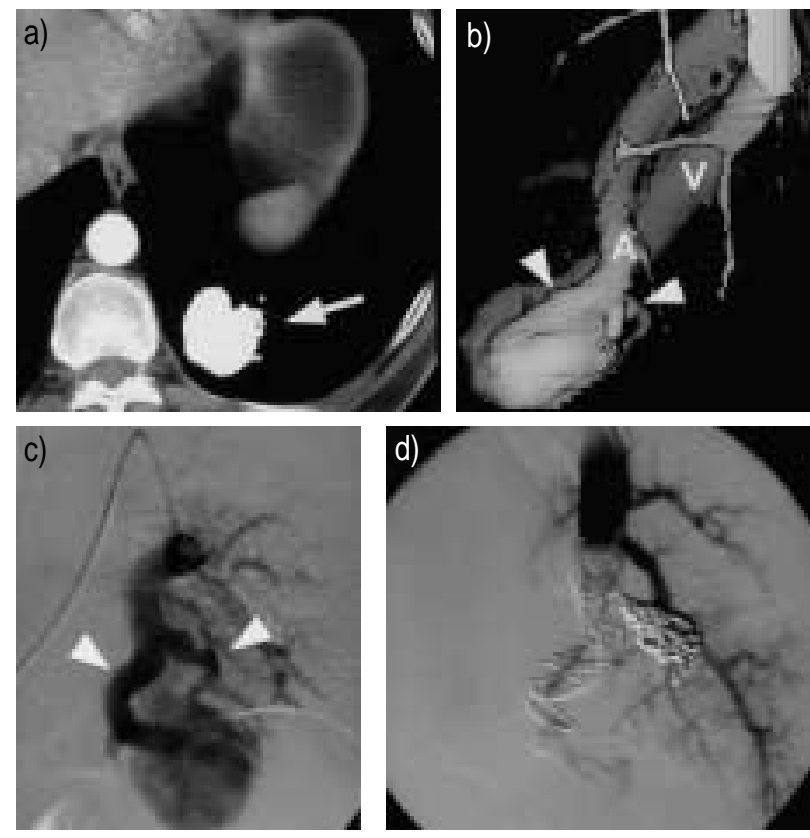

Fig. 11. - Embolization of pulmonary artery vascular malformation (PAVM). A 49-yr-old male presented with polycytaemia in the department of Haematology. Investigations were noncontributive except chest radiography, which depicted a pulmonary mass in the left lower lobe behind the haemidiaphragm. a) Contrast enhanced spiral computed tomography (CT) shows a solitary $3 \mathrm{~cm}$ PAVM (arrow) in the left lower lobe. b) 3D-CT reformatting demonstrates a simple angioarchitecture of the malformation with one feeding artery (A) and one draining vein (V). Note the division of the feeder in small afferent branches (arrowheads) before entering the aneurysmal sac. c) Selective angiographic opacification shows the same findings than in figure (b) (arrowheads). d) Angiography control following embolization with steel coils of the feeding artery close to the aneurysmal sac in order to preserve surrounding parenchymal vascularization. Polycytaemia improved in the following weeks.

the catheter are performed "under water" to avoid air embolism to the brain. Compact placement of endoluminal coils and choice of large "tornado" shaped coils or use of a controlled coil detachment technique are important keypoints for successful treatment to avoid transfistulous coil migration. The site of groin access should be alternated in multiple interventions to avoid femoral vein thrombosis.

Results. Closure rate of PAVMs is $98 \%$ and results in palliation of the right to left shunt and probable prevention of haemorrhagic and thromboembolic complications caused by major PAVMs [136]. There is no evidence based benefit on patient's survival. Multiple treatment sessions are needed in $20-40 \%$ of cases. Embolization can fail in case of a unrecognized persistent feeding artery, recruitment of feeders, including bronchial arteries in $4 \%$ of the cases, recanalization of occluded feeders or growth of other PAVMs.

Complications. Potential complications are encountered in $<10 \%$ of the patients and include pulmonary infarction distal to the occlusion, pleurisy, sepsis and retrograde pulmonary embolism in patients with polycythaemia. 


\section{Pseudoaneurysm}

Destructive processes of any origin, including trauma (particularly iatrogenic, i.e. Swan-Ganz catheter), infection, tumour, and inflammatory disease, can erode the wall of a pulmonary or bronchial vessel, and lead to the formation of a pseudoaneurysm [154]. Prompt therapy is required, as false aneurysms are at risk of enlargement and rupture, which can lead to lethal haemoptysis in $>50 \%$ of the patients [155]. Multiple therapeutic procedures have been used to control pulmonary artery bleeding. Palliative measures include Swan-Ganz balloon tamponade of the affected vessel and endobronchial tube placement with positive end-expiratory pressure. Surgical management generally comprises resection of the involved lobe, or in selected cases, aneurysmectomy [155]. Endoluminal catheter embolization of the parent artery with steel coils has emerged as an alternative noninvasive technique, particularly in emergency cases [154, 156]. Intrasaccular embolization with steel coils has the advantage of preserving the distal pulmonary artery and sparing of pulmonary function distal to the pseudoaneurysm [154] (fig. 12).

\section{Percutaneous recanalization and stenting of the superior vena cava and innominate veins}

\section{Rationale}

The potential of the venous system to collateralize and the usually nonacutely lethal nature of SVC obstruction are the main reasons why medical management and radiotherapy are preferred to other invasive therapeutic procedures for correction. Percutaneous transluminal angioplasty (PTA) is rarely successful in large vein obstruction, due to elastic recoil of the
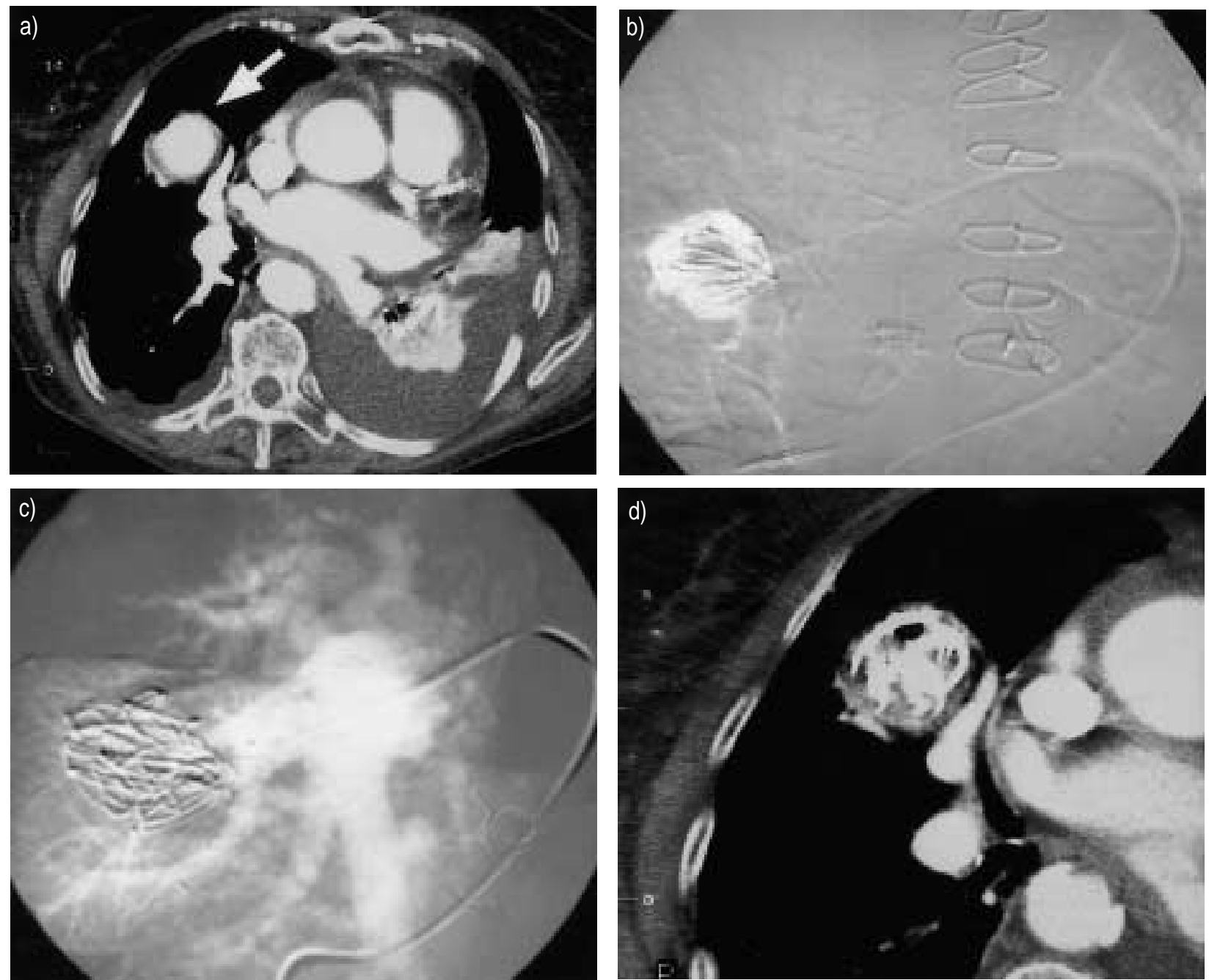

Fig. 12. - Endoluminal intrasaccular embolization of pulmonary artery pseudoaneurysm. An 85-yr-old female presented with haemoptysis 8 days following insertion of a Swan-Ganz catheter. a) Contrast-enhanced spiral computed tomography (CT) demonstrates a 3 cm pseudoaneurysm located in the internal segment of the middle lobe (arrow). b) Angiographic selective catheterization of the internal segmental artery of the middle lobe confirmed the pseudoaneurysm. Intrasaccular embolization of the pseudoaneurysm was performed by filling with ten $15 \mathrm{~cm}$-long, $2 \mathrm{~cm}$-diameter steel coils. c) Angiographic control showed complete occlusion of the pseudoaneurysm and normal perfusion of the middle and lower lobe branches. d) Contrast-enhanced spiral CT scan confirmed complete thrombosis of the pseudoaneurysm. 
venous wall and/or persistent perivascular compression. The rationale for using expandable metal stents in benign and malignant SVC obstruction is the immediate and permanent achievement of venous patency.

\section{Indications}

Potential indications for percutaneous stenting of the SVC and innominate veins are mainly primary or secondary malignant tumours with mediastinal location, such as bronchogenic carcinoma, lymphoma, or metastatic adenopathy and benign stenoses related to central venous lines, haemodialysis shunts, and rarely postoperative anastomotic stenoses, or fibrosing mediastinitis [13, 157-161].

The advantage of endoluminal desobstruction over radiation therapy or chemotherapy is the immediate correction of disabling symptoms and the still possible application in patients who have already received the maximum radiation dose. Patients with imminent SVC obstruction should be treated before they become fully symptomatic, when encasement of the innominate vein, SVC bifurcation is suspected, as a Y-shaped stricture is technically more difficult to treat than a straight vein segment. Multiple and bilateral stents might be required to treat the bifurcation and regional thrombolysis, preceding stent placement might be necessary to clear the lumen from thrombosis before stenting. Patients in whom nephrotoxic chemotherapy or other nephrotoxic drugs are given and patients in whom extensive tumour lysis with hyperuricaemia, hypercalcaemia and emesis-related dehydration is expected may also benefit from SVC desobstruction to increase tolerance of high volume hydration, even if clinical symptoms of venous stasis are not prominent.

Relative contra-indications include preterminal patients with malignant disease, extensive chronic venous thrombosis, endoluminal tumour growth, and upper limb paralysis. Occlusion of the ostium of the azygos vein is not a contraindication. Mechanical thrombectomy using rotational catheters or other devices should not be used in the SVC system, because of the risk of pulmonary embolism by a jugular vein thrombosis, that may become mobilized after successful clearance of the downstream veins. Patients with simultaneous tracheobronchial and mediastinal vein obstruction should undergo stenting of the airways first.

\section{Technique}

Although SVC stenting is a straight forward procedure in simple cases, it can become extremely complex in cases with extensive obstruction. Phlebographic demonstration by a bilateral arm injection of contrast medium is mandatory before treatment, to locate the obstruction, appreciate its haemodynamic significance, extent of collateral venous drainage and any congenital variants and to allow planning of the stenting procedure (fig. 13). In patients with severe oedema of the upper limbs, puncture of the axillary vein may be targeted by a peripheral hand vein injection of carbon dioxide. In case of acute or subacute venous
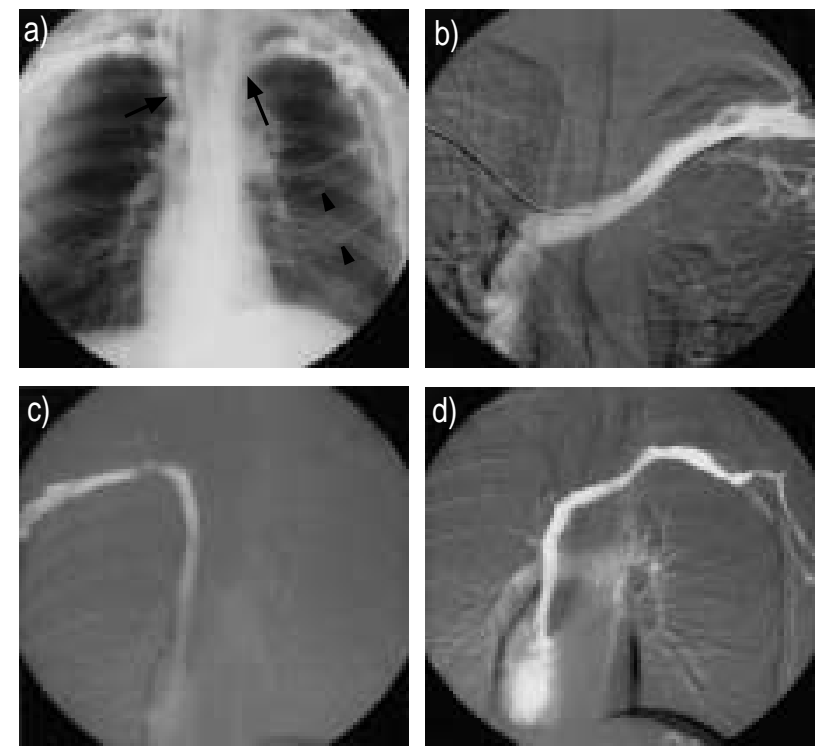

Fig. 13. - A 36-yr-old female with mediastinal non-Hodgkin lymphoma, treated by chemotherapy. Prominent symptoms of superior vena cava obstruction. a) Bilateral arm phlebography shows obstruction of right and left innominate veins (arrows) and lateral thoracic collateral circulation (arrowheads). b) Venous recanalization was performed by a bilateral axillary vein approach. Note recanalized and stented left innominate vein. c) and d) Phlebography shows normal flow in both innominate veins after bilateral stenting with $10 \mathrm{~mm}$ Wallstents.

thrombosis, local catheter directed thrombolysis may be indicated, using an infusion of 70,000-100,000 IU of urokinase per hour or another plasminogen activator. Chronic occlusion is recanalized with catheterguidewire techniques by a unilateral or bilateral axillary vein or a femoral vein approach, or a combination of both. Self-expandable and flexible metal stents are placed, when necessary, multiple and bilateral and in an overlapping position. Stent placement in the subclavian vein should be prohibited because of the risk of subclavian vein thrombosis or stent fragmentation by external clavicular compression. Stents in large veins should be oversized by $25-50 \%$ compared to the diameter of a fully dilated normal vein. PTA is not indicated prior to stenting in malignant disease, but should be performed after stenting to establish optimal venous return immediately. In stenosis of benign origin, PTA is indicated prior to stenting to probe the degree of stenosis and for precise localization of maximum of resistance within the stenosed venous segment. Perprocedure heparinization is advised in all cases [162, 163].

\section{Results}

Following successful restoration of flow in the SVC and innominate veins, complete or significant relief from symptoms is obtained in $68-100 \%$ of patients with malignant disease [158-164]. Delayed reintervention during the patient's survival is only rarely required for a follow-up of 16 months. The type of bare metal stent is irrelevant to clinical results. Covered stents are generally not indicated, as endoluminal tumour extent 
is an exceptional observation. The most prominent clinical symptoms are corrected within a few hours, face and neck oedema resolves in 1-2 days, and upper limb oedema in 2-4 days. Benign SVC obstruction is observed with increasing frequency in recent years. Generally patients with a benign stenosis present at the moment of treatment with extensive thrombosis due to delayed patient referral. Overall, similar results may be obtained in stenosis of malignant and benign origin, although a longer observation time in the benign group allows for more delayed complications to occur. Haemodialysis related central venous stenoses are particularly prone to formation of exuberant intimal hyperplasia within the stent or formation of stenosis in the adjacent venous segment. Repeated PTA or placement of an additional stent may be required during the first years of follow-up. Stents should not be placed in arm veins, as secondary obstruction is the rule $[162,165-168]$.

\section{Complications}

Complications of venous desobstruction are few. Local thrombolysis may lead to haemorrhagic complications. Stent related complications include misplacement or migration, uncomplete stent opening, formation of de novo thrombosis, and pulmonary embolism. Vein perforation, significant infection, phrenic nerve deficit by stent compression or puncture site complications are rare.

\section{Percutaneous vascular foreign body retrieval}

\section{Indications}

Since its introduction, percutaneous catheter mediated vascular foreign body retrieval has emerged as the treatment of choice, avoiding thoracotomy and open heart surgery [12]. The growing clinical application of intravascular devices in interventional radiological practice has increased the risk for central venous embolization of many types of foreign materials besides the classical lost central venous lines, Swan-Ganz catheters, ventriculo-atrial shunts, port-a-caths, cardiac stimulator lines and pacemaker electrodes. All intravascular embolized foreign bodies should be retrieved, as they are potentially associated with serious complications according to their type and location. A $21-71 \%$ long-term serious morbidity and a $25 \%$ death rate was reported [169-173]. Expected complications from a foreign body that is partially or entirely blocked in the right heart are ventricular arrythmia, myocardial infarction, myocarditis, recurrent pericardial effusion, tamponade and sepsis. Foreign bodies blocked in the pulmonary circulation may be responsible for thromboembolism and sepsis. Relative contra-indications of catheter retrieval are free floating thrombus attached to the foreign body and chronic incorporation of the foreign body in a thrombus or vessel wall.

\section{Technique}

Vascular foreign bodies are located with fluoroscopy and, when necessary, phlebographic demonstration.
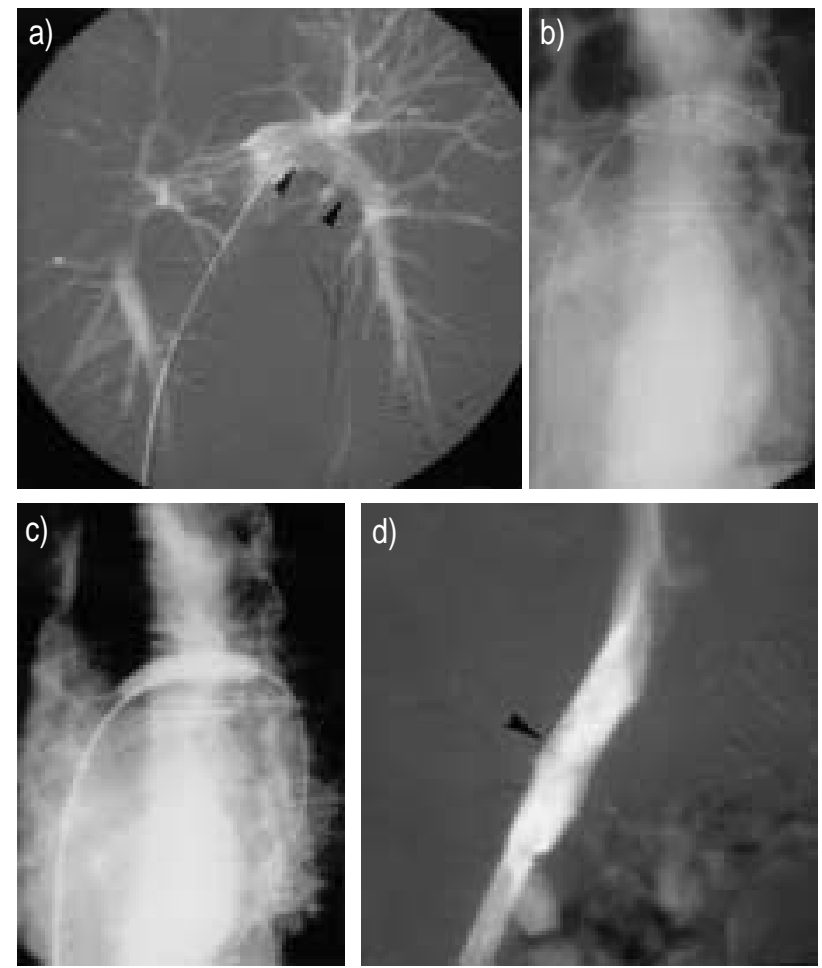

Fig. 14. - Percutaneous vascular foreign body retrieval. A 48-yrold female. Stent placement in the right subclavian vein was attempted in another hospital. The metal stent had migrated to the left pulmonary artery. a) Pulmonary angiography shows a $4 \mathrm{~cm}$ fully expanded metal stent (arrowheads), blocked in the left inferior pulmonary artery. b) Foreign body retrieval was planned with a coaxial balloon extraction technique. The stent lumen was catheterized with a guidewire allowing insertion of a percutaneous transluminal angioplasty (PTA) catheter. c) Full inflation of a PTA balloon inside the stent, allowed atraumatic stent retraction in the iliac vein. d) The stent was abandoned in the right iliac vein, after balloon deflation, avoiding right femoral venotomy for extraction. Control phlebography shows optimal stent placement in the right iliac vein.

Extraction devices are relatively inexpensive and based on the loop-snare technique, helical basket entrapment or the grasping forceps technique or a combination of the above and other catheter-guide wire dislodgement techniques (fig. 14). The procedure is carried out under fluoroscopic control and with local anaesthesia. Large and uncompressible foreign bodies may require a femoral venotomy for extraction. Large stents retrieved from a pulmonary artery or from the heart can be abandoned in an iliac vein.

\section{Results}

The literature reports a success rate of $>90 \%$ by a closed percutaneous retrieval [173]. The procedure may fail, when no free ends of an endovascular line are available for snaring, when small catheter fragments are lodged too far in a small pulmonary artery branch or when small objects are incorporated in the wall of cardiac chambers, or lodged in a thrombosed vein or have perforated outside the venous wall. Failure of percutaneous extraction is obviated by early treatment, 
without waiting for clinical symptoms to occur. Complications from percutaneous retrieval are rare including transient arrythmia, further distal pulmonary embolization of a friable foreign body and thrombosis at the puncture site.

\section{Endoluminal tracheobronchial stenting}

\section{Indications}

Tracheobronchial airway obstruction is a relatively common condition. Various therapeutic options are available and depend on the cause (benign versus malignant), location (central versus peripheral) and origin (intrinsic versus extrinsic) of the stenosis. Patient's condition and the prognosis of disease are also considered. Whenever possible, in malignant obstruction or in benign stenosis, surgery is the first choice [174]. With progress in technique, local treatment by bronchoscopy (laser, cryotherapy, electrocautery, photodynamic therapy, brachytherapy) has been used with increasing frequency [175-179]. Balloon dilatation leads to a rapid improvement of the respiratory function after treatment of malignant and benign bronchial stenosis, but relief of symptoms is often short-lasting [180, 181]. Therefore, indication of stents placement in the tracheobronchial tree has increased in frequency and can be placed under radiological or bronchoscopic control, or a combination of both modalities [181, 182]. Compared to surgery, stent insertion is a simple palliative method, resulting in immediate improvement in acute respiratory distress from airway obstruction [181]. In nonsurgical patients with malignant disease, indications of tracheobronchial stenting are: extrinsic compression or submucosal disease; tracheo-oesophageal fistula; and obstructive endobronchial tumour unresponsive to endobronchial treatment by debulging or resection, respectively [181-190]. In benign stenosis, surgery may not be indicated in patients with a short life expectancy or extensive airway stenoses. Stent insertion for benign stenosis has been reported in the following conditions: iatrogenic (postintubation or postanastomotic stricture); tracheobronchial malacia in children; extrinsic compression from vascular structures or fibrosing mediastinitis; tracheobronchial infection (tuberculosis); and systemic disease (Wegener's granulomatosis, relapsing polychondritis and amyloidosis) [181, 182, 184, 190-196].

\section{Technique}

Precise measurements of the diameter of the tracheal and bronchial lumen and location of the stenosis compared to anatomical landmarks are performed with spiral CT before the procedure. Stents are inserted under sedation or anaesthesia, following previous dilatation or laser ablation of the stenosis under fluoroscopic and endoscopic control. Two types of endobronchial stents are currently available in the tracheobronchial tree: silicone stents (Dumon, Dynamic, Reynders, and others) [181-183, 186, 188,
190] and metallic stents, the latter including either balloon expandable stents (Palmaz and Strecker) or selfexpanding stents (Gianturco, Wallstent, Ultraflex) [181, 182, 187, 190, 192, 193, 197, 198]. Most metallic stents are available in covered and noncovered versions. No ideal stent is currently available. The type of stent to be used is a matter of debate and is often dictated by availability and individual preference. Most metallic stents can be inserted on an outpatient basis.

\section{Results}

Placement of stents leads to an immediate and significant decrease in symptoms and an improvement in respiratory function in $80-95 \%$ of the patients. Most of the patients with severe respiratory impairment are able to be discharged following treatment. As results depend on optimal positioning of the prosthesis and some of the stents show a poor visualization under fluoroscopy, new advances in CT fluoroscopy are promising guiding techniques allowing precise and real time control of stent insertion in selected cases.

\section{Complications}

Complications are related to the type of stent, and include early or late stent migration $(1-19 \%)$, infection $(3-22 \%)$, deformation or breakage $(1-36 \%)$ and stent obstruction by secretions, granulation formation or tumour overgrowth (6-21\%). Other complications, such as major haemorrhage and tracheobronchial fistula are rare. New developments in stent configuration and composition seem to be associated with an easier introduction and a lower rate of complications.

\section{Conclusion}

A close collaboration between interventional radiologists and pathologists, primary care physicians, pulmonologists, medical and radiation oncologists as well as thoracic surgeons is a prerequisite for optimal patient management, offering full therapeutic options. Future developments in imaging based patient management mainly concern oncological applications. Following preliminary studies on percutaneous treatment of inoperable or early non-small cell lung cancer, such as electrochemical polarization of cancer [199], new modalities are emerging including percutaneous brachytherapy [200] and radiofrequency tumour ablation [201]. Interventional radiology will also be used for catheter or needle mediated immunomodulatory or gene therapy delivery to the target organs. Concerning stenting procedures, future types of stents include hybrid stents with metallic components and a smooth synthetic covering of silicone or polyurethane, biodegradable stents, chemically and radioactively coated stents [182, 202]. 


\section{References}

1. Leyden OO. Über infectiöse Pneumonie. Dtsch Med Wochenschr 1883; 9: 52-55.

2. Hattori S, Matsuda M, Sugiyama T. Cytologic diagnosis of early lung cancer: brushing methods under X-ray television fluoroscopy. Dis Chest 1964; 45: 129-135.

3. Dahlgren S, Nordenstrom B. Transthoracic needle biopsy. Stockholm, Almquist and Wiksell, 1966.

4. Nordenström B. Transjugular approach to the mediastinum for mediastinal needle bopsy. Invest Radiol 1967; 2: 134-140.

5. Nordenström B. Paraxiphoid approach to the mediastinum for mediastinography and mediastinal needle bopsy. Invest Radiol 1967; 2: 141-146.

6. Condorelli L. Il pneumomediastino artificiale. Minerva Med 1936; 27: 81-86.

7. Vainrub D, Husher DM, Guinn GA, Young EJ, Septimus EJ, Travis LL. Percutaneous drainage of lung abscess. Am Rev Respir Dis 1978; 117: 153-157.

8. Boijen E, Dalbäck O, Kugelberg J, Schuller H, Zsigmond $\mathrm{M}$. Die Behandlung des inoperablen Bronchuskarzinoms mit Zytostaticainfusionen via A.A. bronchiales. Thoraxchir Vas Chir 1964; 12: 198-201.

9. Remy J, Voisin C, Dupuis C, et al. Traitement des hémoptysies par embolisation de la circulation systémique. Ann Radiol 1974; 17: 5-16.

10. Remy J, Lemaitre L. Management of severe hemoptysis by endovascular occlusion. Pract Cardiol 1983; 9: $117-122$

11. Portsmann W. Therapeutic embolization of arteriovenous pulmonary fistula by catheter technique. In: Kelof O, ed. Current Concepts in Paediatric Radiology. Berlin, Springer, 1977; pp. 23-31.

12. Thomas J, Sinclair Smith B, Bloomfield D, Davachi A. Non surgical retrieval of broken segment of steel spring guide from right atrium and inferior vena cava. Circulation 1964; 30: 106-108.

13. Rosch J, Bedell JE, Putnam J, Antonovic R, Uchida B. Gianturco expandable wire stents in the treatment of superior vena cava syndrome recurring after maximum tolerance radiation. Cancer 1987; 60: 1243-1246.

14. Ghaye B, Dondelinger RF. Percutaneous Imaging Guided Interventional Procedures in the Thorax. In: Bolliger CT, Mathur PN, eds. Interventional Bronchoscopy (Respiratory Research, vol. 30). Karger, Basel, 1999; 198-214.

15. Klein JS, Zarka M. Transthoracic needle biopsy: An overview. J Thorac Imag 1997; 12: 232-249.

16. Flower CDR, Verney GI. Percutaneous needle biopsy of the thoracic lesions: an evaluation of 300 biopsies. Clin Radiol 1979; 30: 215-218.

17. Westcott JL. Percutaneous catheter drainage of pleural effusion and empyema. AJR Am J Roentgenology 1985; 144: 1189-1193.

18. Perlmutt LM, Braun SD, Newman GE, et al. Transthoracic needle aspiration: use of a small chest tube to treat pneumothorax. AJR Am J Roentgenology 1987; 148: 849-851.

19. Casola G, van Sonnenberg E, Keightley A, Ho M, Withers C, Lee AS. Pneumothorax: Radiologic treatment with small catheters. Radiology 1988; 166: 89-91.

20. Hunnam GR, Flower CDR. Radiologically-guided percutaneous catheter drainage of empyemas. Clin Radiol 1988; 39: 121-126.
21. Merriam MA, Cronan JJ, Dorfman GS, Lambiase RE, Haas RA. Radiographically guided percutaneous catheter drainage of pleural fluid collections. AJR Am J Roentgenology 1988; 151: 1113-1116.

22. Silverman SG, Mueller PR, Saini S, et al. Thoracic empyema: management with image-guided catheter drainage. Radiology 1988; 169: 5-9.

23. Moulton JS, Moore PT, Mencini RA. Treatment of loculated pleural effusions with transcatheter intracavitary Urokinase. AJR Am J Roentgenology 1989; 153: 941-945.

24. Parker LA, Charnock GC, Delany DJ. Small bore catheter drainage and sclerotherpay for malignant pleural effusions. Cancer 1989; 64: 1218-1221.

25. Reinhold C, Illescas FF, Atri M, Bret PM. Treatment of pleural effusions and pneumothorax with catheters placed percutaneously under imaging guidance. $A J R$ Am J Roentgenology 1989; 152: 1189-1191.

26. Lee KS, Im JG, Kim YH, Hwang SH, Bae WK, Lee $\mathrm{BH}$. Treatment of thoracic multiloculated empyemas with intracavitary Urokinase: a prospective study. Radiology 1991; 179: 771-775.

27. Lambiase RE, Deyoe L, Cronan JJ, Dorfman GS. Percutaneous drainage of 335 consecutive abscesses: Result of primary drainage with 1-year follow-up. Radiology 1992; 184: 167-179.

28. van Sonnenberg E, Nakamoto SK, Mueller PR, et al. $\mathrm{CT}$ and ultrasound-guided catheter drainage of empyemas after chest-tube failure. Radiology 1984; 151: 349-353.

29. van Sonnenberg E, Casola G, Ho M, et al. Difficult thoracic lesions: CT-guided biopsy experience in 150 cases. Radiology 1988; 167: 457-461.

30. Ball WS Jr, Bisset GS, Towbin RB. Percutaneous drainage of chest abscesses in children. Radiology 1989; 171: 431-434.

31. Dondelinger RF, Kurdziel JC. Percutaneous drainage of thoracic fluid collections. In: Dondelinger RF, Rossi $\mathrm{P}$, Kurdziel JC, Wallace $\mathrm{S}$, eds. Interventional Radiology. Stuttgart, New-York, Thieme, 1990; pp. $142-155$.

32. Neff CC, van Sonnenberg E, Lawson DW, Patton AS. CT follow-up of empyemas: pleural peels resolve after percutaneous catheter drainage. Radiology 1990; 176: 195-197.

33. van Sonnenberg E, D'Agostino HB, Casola G, Wittich GR, Varney RR, Harker C. Lung abscess: CT-guided drainage. Radiology 1991; 178: 347-351.

34. Protopapas Z, Westcott JL. Transthoracic needle biopsy of mediastinal lymph nodes for staging lung and other cancers. Radiology 1996; 199: 489-496.

35. Ghaye B, Dondelinger RF. Percutaneous CT guided lung biopsy: Sequential versus spiral scanning. A randomized prospective study. Eur Radiol 1999; 9: $1317-1320$.

36. Katada K, Kato R, Anno H, et al. Guidance with realtime CT fluoroscopy: Early clinical experience. Radiology 1996; 200: 851-856.

37. White CS, Meyer CA, Templeton PA. CT fluoroscopy for thoracic interventional procedures. Radiol Clin $N$ Am 2000; 38: 303-322.

38. Heilo A, Stenwig AE, Solheim OP. Malignant pleural mesothelioma: US-guided histologic core-needle biopsy. Radiology 1999; 211: 657-659.

39. Heilo A. Tumors in the mediastinum: US-guided histologic core-needle biopsy. Radiology 1993; 189: 143-146. 
40. Parker LA, Melton JW, Delany DJ, Yakaskas BC. Percutaneous small bore catheter drainage in the management of lung abscesses. Chest 1987; 92: 213218.

41. O'Moore PV, Mueller PR, Simeone JF, et al. Sonographic guidance in diagnostic and therapeutic interventions in the pleural space. AJR Am $J$ Roentgenology 1987; 149: 1-5.

42. Cummin ARC, Wright NL, Joseph AE. Suction drainage: a new approach to the treatment of empyema. Thorax 1991; 46: 259-260.

43. Morrison MC, Mueller PR, Lee MJ, et al. Sclerotherapy of malignant pleural effusion through sonographically placed small-bore catheters. AJR Am J Roentgenology 1992; 158: 41-43.

44. Yang PC, Luh KT, Lee YC, et al. Lung abscesses: US examination and US-guided transthoracic aspiration. Radiology 1991; 180: 171-177.

45. Yang PC, Chang DB, Yu CJ, et al. Ultrasound-guided core biopsy of thoracic tumors. Am Rev Respir Dis 1992; 146: 763-767.

46. Pan JF, Yang PC, Chang DB, Lee YC, Kuo SH, Luh RT. Needle aspiration biopsy of malignant lung masses with necrotic centers. Improved sensitivity with ultrasound guidance. Chest 1993; 103: 1452-1456.

47. Rubens DJ, Strang JG, Fultz PJ, Gottlieb RH. Sonographic guidance of mediastinal biopsy: An effective alternative to $\mathrm{CT}$ guidance. AJR $\mathrm{Am}$ J Roentgenology 1997; 169: 1605-1610.

48. Mueller PR, Stark DD, Simeone JF, et al. MR-guided aspiration biopsy: needle design and clinical trials. Radiology 1986; 161: 605-609.

49. Lufkin R, Teresi L, Hanafee W. New needle for MRguided aspiration cytology of the head and neck. AJR Am J Roentgenology 1987; 149: 380-382.

50. Strautman PR, Dorfman GS, Haas RA. Prebiopsy wire localization of a small peripheral lung nodule. J Vasc Interv Radiol 1992; 3: 391-393.

51. Shah RM, Spirn PW, Salazar AM, et al. Localization of peripheral pulmonary nodules for thoracoscopic excision: value of CT-guided wire placement. AJR Am J Roentgenology 1993; 161: 279-283.

52. Templeton PA, Krasna M. Localization of pulmonary nodules for thoracoscopic resection: use of needle/wire breast-biopsy system. AJR Am J Roentgenology 1993; 160: 761-762.

53. Spirn PW, Shah RM, Steiner RM, Greenfield AL, Salazar AM, Liu JB. Image-guided localization for video-assisted thoracic surgery. J Thorac Imag 1997; 12: 285-292.

54. Klein JS, Zarka MA. Transthoracic needle biopsy. Radiol Clin N Am 2000; 38: 235-266.

55. Westcott JL. Direct percutaneous needle aspiration of localized pulmonary lesions: results in 422 patients. Radiology 1980; 137: 31-35.

56. Greene R. Transthoracic needle aspiration biopsy. In: Athanasoulis CA, Pfister RC, Greene R, Roberson $\mathrm{GH}$, eds. Interventional Radiology. Philadelphia, Saunders, 1982; pp. 587-634.

57. Calhoun P, Feldman PS, Armstrong P, et al. The clinical outcome of needle aspirations of the lung when cancer is not diagnosed. Ann Thorac Surg 1986; 41: 592-596.

58. Greene R, Szyfelbein WM, Isler RJ, Stark P, Jantsch H. Supplementary tissue-core histology from fineneedle transthoracic aspiration biopsy. AJR Am J Roentgenology 1985; 144: 787-792.
59. Khouri NF, Stitik FP, Erozan YS, et al. Transthoracic needle aspiration biopsy of benign and malignant lung lesions. AJR Am J Roentgenology 1985; 144: 281288.

60. Horrigan TP, Bergin KT, Snow N. Correlation between needle biopsy of lung tumors and histopathologic analysis of resected specimens. Chest 1986; 90: 638-640.

61. Winning AJ, McIvor J, Seed WA, Husain OAN, Metaxas N. Interpretation of negative results in fine needle aspiration of discrete pulmonary lesions. Thorax 1986; 41: 875-879.

62. Johnston WW. Fine needle aspiration biopsy versus sputum and bronchial material in the diagnosis of lung cancer. A comparative study of 168 patients. Acta Cytol 1988; 32: 641-645.

63. Charig MJ, Stutley JE, Padley SPG, Hansell DM. The value of negative needle biopsy in suspected operable lung cancer. Clin Radiol 1991; 44: 147-149.

64. Sinner WN. Wert und Bedeutung der perkutanen transthorakalen Nadelbiopsie für die Diagnose intrathorakaler Krankheitprozesse. ROFO 1975; 123 : 197-202.

65. Westcott JL, Rao N, Colley DP. Transthoracic needle biopsy of small pulmonary nodules. Radiology 1997; 202: 97-103.

66. Laurent F, Latrabe V, Vergier B, Montaudon M, Vernejoux JM, Dubrez J. CT-guided transthoracic needle biopsy of pulmonary nodules smaller than $20 \mathrm{~mm}$ : results with an automated 20-gauge coaxial cutting needle. Clin Radiol 2000; 55: 281-287.

67. Noppen MM, De Mey J, Meysman M, Opdebeeck B, Vincken WG, Osteaux M. Percutaneous needle biopsy of localized pulmonary, mediastinal, and pleural diseased tissue with an automated guillotine softtissue needle. Chest 1995; 107: 1615-1620.

68. Klein JS, Salomon G, Stewart EA. Transthoracic needle biopsy with a coaxially placed 20-gauge automated cutting needle: results in 122 patients. Radiology 1996; 198: 715-720.

69. Boiselle PM, Shepard JA, Mark EJ, et al. Routine addition of an automated biopsy device to fine-needle aspiration of the lung: a prospective assessment. $A J R$ Am J Roentgenology 1997; 169: 661-666.

70. Hayashi N, Sakai T, Kitagawa M, et al. CT-guided biopsy of pulmonary nodules less than $3 \mathrm{~cm}$ : usefulness of the spring-operated core biopsy needle and frozen-section pathologic diagnosis. $A J R \quad A m$ J Roentgenology 1998; 170: 329-331.

71. Lucidarme O, Howarth N, Finet JF, Grenier PA. Intrapulmonary lesions: percutaneous automated biopsy with a detachable, 18-gauge, coaxial cutting needle. Radiology 1998; 207: 759-765.

72. Greif J, Marmur S, Schwarz Y, Man A, Staroselsky AN. Percutaneous core cutting needle biopsy compared with fine-needle aspiration in the diagnosis of peripheral lung malignant lesions: results in 156 patients. Cancer 1998; 84: 144-147.

73. Greif J, Marmur S, Schwarz Y, Staroselsky AN. Percutaneous core needle biopsy vs. fine needle aspiration in diagnosing benign lung lesions. Acta Cytol 1999; 43: 756-760.

74. Laurent F, Latrabe V, Vergier B, Michel P. Percutaneous CT-guided biopsy of the lung: comparison between aspiration and automated cutting needles using a coaxial technique. Cardiovasc Intervent Radiol 2000; 23: 266-272. 
75. Scott EM, Marshall TJ, Flower CD, Stewart S. Diffuse pleural thickening: Percutaneous CT-guided cutting needle biopsy. Radiology 1995; 194: 867-870.

76. Ben Yehuda D, Polliak A, Okon E, et al. Image-guided core needle biopsy in malignant lymphoma: Experience with 100 patients that suggests the technique is reliable. J Clin Oncol 1996; 14: 2431-2434.

77. Pappa VI, Hussain HK, Reznek RH, et al. Role of image-guided core needle biopsy in the management of patients with lymphoma. J Clin Oncol 1996; 14: $2427-$ 2430.

78. Zinzani PL, Corneli G, Cancellieri A, et al. Core needle biopsy is effective in the initial diagnosis of mediastinal lymphoma. Haematologica 1999; 84: 600 603.

79. Greif J, Staroselsky AN, Gernjac M, et al. Percutaneous core needle biopsy in the diagnosis of mediastinal tumors. Lung Cancer 1999; 25: 169-173.

80. Klose KC. CT-guided large-bore biopsy: extrapleural injection of saline for safe transpleural access to pulmonary lesions. Cardiovasc Intervent Radiol 1993; 16: 259-261.

81. Langen HJ, Klose KC, Keulers P, Adam G, Jochims M, Günther RW. Artificial widening of the mediastinum to gain access for extrapleural biopsy: clinical results. Radiology 1995; 196: 703-706.

82. Ayar D, Golla B, Lee JY, Nath H. Needle-track metastasis after transthoracic needle biopsy. $J$ Thorac Imag 1998; 13: 2-6.

83. Wong RS, Ketai L, Temes RT, Follis FM, Ashby R. Air embolus complicating transthoracic percutaneous needle biopsy. Ann Thorac Surg 1995; 59: 1010-1011.

84. Lee SI, Shepard JO, Boiselle PM, Trotman-Dickenson B, McLoud TC. Role of transthoracic needle biopsy in patient treatment decisions. Radiology 1996; 20(P): 269.

85. Light RW. Parapneumonic effusions and empyema. Clin Chest Med 1985; 6: 55-62.

86. Ghaye B, Dondelinger RF, Dorthu L. Aspiration et drainage percutanés des collections thoraciques. $I n$ : Gangi A, Dietemann JL. eds. Tomodensitométrie interventionelle. Paris, Vigot, 1994; 113-131.

87. Moulton JS. Image-guided management of complicated pleural fluid collections. Radiol Clin $N \mathrm{Am}$ 2000; 38: 345-374.

88. Vianna NJ. Nontuberculous bacterial empyema in patients with and without underlying disease. JAMA 1971; 215: 69-75.

89. Cassina PC, Hauser M, Hillejan L, Greschuchna D, Stamatis G. Video-assisted thoracoscopy in the treatment of pleural empyema: stage-based management and outcome. J Thorac Cardiovasc Surg 1999; 117: 234-238.

90. Bergh NP, Ekroth R, Larsson S, Nagy P. Intrapleural Streptokinase in the treatment of haemothorax and empyema. Scan J Thor Cardiovasc Surg 1977; 11: 265268.

91. Berglin E, Ekroth R, Teger-Nilsson AC, WilliamOlsson G. Intrapleural instillation of Streptokinase: effects on systemic fibrinolysis. Thorac Cardiovasc Surg 1981; 29: 124-126.

92. Fraedrich G, Hoffman D, Effenhauser P, Jander R. Instillation of fibrinolytic enzymes in treatment of pleural empyema. Thorac Cardiovasc Surg 1982; 30: 36-38.

93. Aye RW, Froese DP, Hill LD. Use of purified
Streptokinase in empyema and hemothorax. $A m$ J Surg 1991; 161: 560-562.

94. Henke CA, Leatherman JW. Intrapleurally administered Streptokinase in the treatment of acute loculated nonpurulent parapneumonic effusions. $\mathrm{Am}$ Rev Respir Dis 1992; 145: 680-684.

95. Robinson LA, Moulton AL, Fleming WH, Alonso A, Galbraith TA. Intrapleural fibrinolytic treatment of multiloculated thoracic empyemas. Ann Thorac Surg 1994; 57: 803-814.

96. Taylor RFH, Rubens MB, Pearson MC, Barnes NC. Intrapleural streptokinase in the management of empyema. Thorax 1994; 49: 856-859.

97. Pollack JS, Passik CS. Intrapleural urokinase in the treatment of loculated pleural effusions. Chest 1994; 105: 868-873.

98. Moulton SM, Benkert RE, Weisiger KH, Chambers JA. Treatment of complicated pleural fluid collections with image-guided drainage and intracavitary urokinase. Chest 1995; 108: 1252-1259.

99. Park CS, Chung WM, Lim MK, Cho $\mathrm{CH}$, Suh $\mathrm{CH}$, Chung WK. Transcatheter instillation of urokinase into loculated pleural effusion: Analysis of treatment effect. AJR Am J Roentgenology 1996; 167: 649-652.

100. Jerjes-Sanchez C, Ramirez-Rivera A, Elizalde JJ, et al. Intrapleural fibrinolysis with streptokinase as an adjunctive treatment in hemothorax and empyema. Chest 1996; 109: 1514-1519.

101. Temes RT, Follis F, Kessler RM, Pett SB, Wernly JA. Intrapleural fibrinolytics in management of empyema thoracis. Chest 1996; 110: 102-106.

102. Davies RJO, Traill ZC, Gleeson FV. Randomised controlled trial of intrapleural streptokinase in community acquired pleural infection. Thorax 1997; 52: 416-421.

103. Bouros D, Schiza S, Patsourakis G, Chalkiadakis G, Panagou P, Siafakas NM. Intrapleural streptokinase versus urokinase in the treatment of complicated parapneumonic effusions. A prospective, doubleblind study. Am J Respir Crit Care Med 1997; 155: 291-295.

104. Chin NK, Lim TK. Controlled trial of intrapleural streptokinase in the treatment of pleural empyema and complicated parapneumonic effusions. Chest 1997; 111: 275-279.

105. Seaton KG, Patz EF Jr, Goodman PC. Palliative treatment of malignant pleural effusions: value of small-bore catheter thoracostomy and doxycycline sclerotherapy. AJR Am J Roentgenology 1995; 164 : 589-591.

106. Patz EF Jr, McAdams P, Goodman PC, Blackwell S, Crawford J. Ambulatory sclerotherapy for malignant pleural effusions. Radiology 1996; 199: 133-135.

107. Erasmus JJ, Goodman PC, Patz EF Jr. Management of malignant pleural effusions and pneumothorax. Radiol Clin N Am 2000; 38: 375-383.

108. Conces DJ Jr, Tarver RD, Gray WC, Pearcy EA. Treatment of pneumothoraces utilizing small caliber chest tubes. Chest 1988; 94: 55-57.

109. Lorenzo RL, Bradford BF, Black J, Smith CD. Lung abscesses in children: diagnostic and therapeutic needle aspiration. Radiology 1985; 157: 79-80.

110. Rami-Porta R, Bravo-Bravo JL, Alix-Trueba A, Serrano-Munoz F. Percutaneous drainage of lung abscess. J Thorac Cardiovasc Surg 1985; 89: 314-317.

111. Yellin A, Yellin EO, Lierman Y. Percutaneous tube 
drainage: the treatment of choice for refractory lung abscess. Ann Thorac Surg 1985; 39: 266-270.

112. Rice TW, Ginsberg RJ, Todd TRJ. Tube drainage of lung abscesses. Ann Thorac Surg 1987; 44: 356-359.

113. Ha HK, Kang MW, Park JM, Yang WJ, Shinn KS, Bahk YW. Lung abscess. Percutaneous catheter therapy. Acta Radiol 1993; 34: 362-365.

114. Uflacker R, Kaemmerer A, Neves C, Picon PD. Management of massive hemoptysis by bronchial artery embolization. Radiology 1983; 146: 627-634.

115. Rabkin JE, Astafjev VI, Gothman LN, Grigorjev YG. Transcatheter embolization in the management of pulmonary hemorrhage. Radiology 1987; 163: 361365.

116. Shirakusa T, Ueda H, Saito T, Matsuba K, Kouno J, Hirota N. Surgical treatment of pulmonary aspergilloma and Aspergillus empyema. Ann Thorac Surg 1989; 48: 779-782.

117. Munk PL, Vellet AD, Rankin RN, Muller NL, Ahmad D. Intracavitary aspergilloma: Transthoracic percutaneous injection of amphotericin gelatin solution. Radiology 1993; 188: 821-823.

118. Giron JM, Poey CG, Fajadet PP, et al. Inoperable pulmonary aspergilloma: Percutaneous CT-guided injection with glycerin and amphotericin B paste in 15 cases. Radiology 1993; 188: 825-827.

119. Klein JS, Fang K, Chang MC. Percutaneous transcatheter treatment of an intracavitary aspergilloma. Cardiovasc Intervent Radiol 1993; 16: 321-324.

120. Giron J, Poey C, Fajadet P, et al. CT-guided percutaneous treatment of inoperable pulmonary aspergillomas: A study of 40 cases. Eur J Radiol 1998; 28: 235-242.

121. Jackson M, Flower CD, Shneerson JM. Treatment of symptomatic pulmonary aspergillomas with intracavitary instillation of amphotericin B through an indwelling catheter. Thorax 1993; 48: 928-930.

122. Sewall LE, Franco AI, Wojtowycz MM, Mc Dermott JC. Pneumatoceles causing respiratory compromise. Treatment by percutaneous decompression. Chest 1993; 103: 1266-1267.

123. Meranze SG, LeVeen RF, Burke DR, Cope C, McLean GK. Transesophageal drainage of mediastinal abscesses. Radiology 1987; 165: 395-398.

124. Gobien RP, Stanley JH, Gobien BS, Vujic I, Pass HI. Percutaneous catheter aspiration and drainage of suspected mediastinal abscesses. Radiology 1984; 151: 69-71.

125. Carrol CL, Jeffrez RB Jr, Federle MP, Vernacchia FS. CT evaluation of mediastinal infections. J Comput Assist Tomogr 1987; 11: 449-453.

126. Callahan JA, Seward JB, Nishimura RA, et al. Twodimensional echocardiographically guided pericardiocentesis: experience in 117 consecutive patients. $\mathrm{Am}$ J Cardiol 1985; 55: 476-479.

127. Szapiro D, Ghaye B, Dondelinger RF. Pericardial tamponade: CT-guided percutaneous drainage. J Interv Radiol 1996; 11: 129-131.

128. Dondelinger RF, Coulon M, Kurdziel JC, Hemmer M. Tension mediastinal emphysema: emergency percutaneous drainage with CT guidance. Eur J Radiol 1992; 15: 7-10.

129. Gourin A, Garzon AA. Operative treatment of massive hemoptysis. Ann Thorac Surg 1974; 18: 52-60.

130. Bobrowitz ID, Ramakrishna S, Shim YS. Comparison of medical versus surgical treatment of major hemoptysis. Arch Intern Med 1983; 143: 1343-1346.
131. Magilligan DJ Jr, Ravipati S, Zayat P, Shetty PC, Bower G, Kvale P. Massive hemoptysis: Control by transcatheter bronchial artery embolization. Ann Thorac Surg 1981; 32: 392-400.

132. Remy-Jardin M, Remy J. Embolization for the treatment of hemoptysis. In: Kadir S, ed. Current practice of interventional radiology. Philadelphia, BC Decker Inc., 1991; pp. 194-202.

133. Fernando HC, Stein M, Benfield JR, Link DP. Role of bronchial artery embolization in the management of hemoptysis. Arch Surg 1998; 133: 862-866.

134. Cremaschi P, Nascimbene C, Vitulo P, et al. Therapeutic embolization of bronchial artery: A successful treatment in 209 cases of relapse hemoptysis. Angiology 1993; 44: 295-299.

135. Knott-Craig CJ, Oostuizen JG, Rossouw G, Joubert JR, Barnard PM. Management and prognosis of massive hemoptysis. Recent experience with 120 patients. J Thorac Cardiovasc Surg 1993; 105: 394-397.

136. Saluja S, Henderson KJ, White RI Jr. Embolotherapy in the bronchial and pulmonary circulations. Radiol Clin N Am 2000; 38: 425-447.

137. Tanaka N, Yamakado $\mathrm{K}$, Murashima $\mathrm{S}$, et al. Superselective bronchial artery embolization for hemoptysis with a coaxial microcatheter system. J Vasc Intervent Radiol 1997; 8: 65-70.

138. White RI Jr. Bronchial artery embolotherapy for control of acute hemoptysis. Chest 1999; 115: 912-914.

139. Keller FS, Rösch J, Lofflin TG, Nath PH, McElvein RB. Nonbronchial systemic collateral arteries: Significance in percutaneous embolotherapy for hemoptysis. Radiology 1987; 164: 687-692.

140. Jardin M, Remy J. Control of hemoptysis: Systemic angiography and anastomosis of the internal mammary artery. Radiology 1988; 168: 377-382.

141. Tamura S, Kodama T, Otsuka N, et al. Embolotherapy for persistent hemoptysis: The significance of pleural thickening. Cardiovasc Intervent Radiol 1993; 16: 85-88.

142. Garcia-Medina J, Casal M, Fernandez-Villar A. Embolization of bronchial arteries in patients with hemoptysis: Influence of underlying pathology on outcome. J Intervent Radiol 1999; 14: 171-180.

143. Cohen AM, Doershuk CF, Stern RC. Bronchial artery embolization to control hemoptysis in cystic fibrosis. Radiology 1990; 175: 401-405.

144. Dines DE, Seward JB, Bernatz PE. Pulmonary arteriovenous fistulas. Mayo Clin Proc 1983; 58: 176-181.

145. Burke CM, Safai C, Nelson DP, Raffin TA. Pulmonary arteriovenous malformations: A critical update. Am Rev Respir Dis 1986; 134: 334-339.

146. White RI Jr, Lynch-Nyhan A, Terry $\mathrm{P}$, et al. Pulmonary arteriovenous malformations: Techniques and long-term outcome of embolotherapy. Radiology 1988; 169: 663-669.

147. Andersen PE, Kjeldsen AD, Oxhoj H, Vase P. Percutaneous transluminal treatment of pulmonary arteriovenous malformations. J Intervent Radiol 1999; 14: $164-170$.

148. Remy J, Remy-Jardin M, Wattinne L, Deffontaines C. Pulmonary arteriovenous malformations: Evaluation with CT of the chest before and after treatment. Radiology 1992; 182: 809-816.

149. Remy J, Remy-Jardin M, Giraud F, Wattinne L. Angioarchitecture of pulmonary arteriovenous malformations: clinical utility of three-dimensional helical CT. Radiology 1994; 191: 657-664. 
150. White RI Jr, Mitchell SE, Barth $\mathrm{KH}$, et al. Angioarchitecture of pulmonary arteriovenous malformations: an important consideration before embolotherapy. AJR Am J Roentgenology 1983; 140: 681-686.

151. Hugues JM, Allison DJ. Pulmonary arteriovenous malformations: The radiologist replaces the surgeon. Clin Radiol 1990; 41: 297-298.

152. White RI, Pollak JS. Pulmonary arteriovenous malformations: Options for management. Ann Thorac Surg 1994; 57: 516-524.

153. Dutton JA, Jackson JE, Hugues JM, et al. Pulmonary arteriovenous malformations: Results of treatment with coil embolization in 53 patients. AJR Am J Roentgenology 1995; 165: 1119-1125.

154. Ghaye B, Trotteur G, Dondelinger RF. Multiple pulmonary artery pseudoaneurysms: intrasaccular embolization. Eur Radiol 1997; 7: 176-179.

155. Ungaro R, Saab S, Almond CH, Kumar S. Solitary peripheral pulmonary artery aneurysms: pathogenesis and surgical treatment. J Thorac Cardiovasc Surg 1976; 71: 566-571.

156. Remy J, Smith M, Lemaitre L, Marache P, Fournier E. Treatment of massive hemoptysis by occlusion of a Rasmussen aneurysm. AJR Am J Roentgenology 1980; 135: 605-606.

157. Putman JS, Uchita BT, Antonovic R, Rösch J. Superior vena cava syndrome associated with massive thrombosis: treatment with expandable wire stents. Radiology 1988; 167: 727-728.

158. Dondelinger RF, Goffette P, Kurdziel JC, Roche A. Expandable metal stents for stenoses of the venae cavae and large veins. Semin Intervent Radiol 1991; 8: 252-263.

159. Rosch J, Uchida BT, Hall LD, et al. Gianturco selfexpanding stents: clinical experience in the vena cava and large veins. Cardiovasc Intervent Radiol 1992; 15: 319-327.

160. Irving JD, Dondelinger RF, Reidy JF, et al. Gianturco self-expanding stents: clinical experience in the vena cava and large veins. Cardiovasc Intervent Radiol 1992; 15: 328-333.

161. Furui S, Sawada S, Kuramoto K, et al. Gianturco stent placement in malignant caval obstruction: analysis of factors for predicting the outcome. Radiology 1995; 195: 147-152.

162. Dondelinger RF, Capasso P, Tancredi T, Trotteur G. Metal stents in the venous system. In: Adam A, Dondelinger RF, Mueller PR, eds. Textbook of Metallic Stents. Oxford, Isis Medical Media, 1997.

163. Trerotola SO. Interventional Radiology in central venous stenosis and occlusion. Semin Intervent Radiol 1994; 11: 291-304.

164. Gaines PA, Belli AM, Anderson PB, McBride K, Hemingway AP. Superior vena caval obstruction managed by Gianturco Z stent. Clin Radiol 1994; 49: 207-208.

165. Glanz S, Gordon DH, Butt KM, Hong J, Lipkovitz GS. The role of percutaneous angioplasty in the management of chronic hemodialysis fistulas. Ann Surg 1987; 206: 777-781.

166. Quinn SF, Schuman ES, Hall L, et al. Venous stenoses in patients who undergo hemodialysis: treatment with self-expandable endovascular stents. Radiology 1992; 183: 499-504.

167. Beathard GA. Percutaneous transvenous angioplasty in the treatment of vascular access stent. Kidney Int 1992; 42: 1390-1397.

168. Vorwerk D, Aachen G, Guenther RW, Bohndorf K, Gladziwa U, Kistler D. Self-expanding stents in peripheral and central veins used for arteriovenous shunts: five years of experience. Radiology 1993; 189: 174.

169. Fisher RG, Ferreyo R. Evaluation of current techniques for nonsurgical removal of intravascular iatrogenic foreign bodies. AJR Am J Roentgenology 1978; 130: 541-548.

170. Richardson JD, Grover FL, Trinkle JK. Intravenous catheter emboli: experience with twenty cases and collective review. Am J Surg 1974; 128: 722-727.

171. Burri C, Henkeneyer H, Passler H. Katheterembolien. Schweiz Med Wschr 1971; 101: 1537-1541.

172. Schuler S, Hetzger R, Stegman T, Borst HG. Surgical therapy of intracardiac infected pacemaker electrodes and catheter remnants. Z Kardiol 1986; 75: 151-155.

173. Dondelinger RF, Lepoutre B, Kurdziel JC. Percutaneous vascular foreign body retrieval: experience of an 11-year period. Eur J Radiol 1991; 12: 4-10.

174. Bolliger CT. Multimodality treatment of advanced pulmonary malignancies. In: Bolliger $\mathrm{CT}$, Mathur $\mathrm{PN}$, eds. Interventional bronchoscopy. Respiratory Research, vol. 30. Basel, Karger, 1999; vol 30. pp. 187196.

175. Cavaliere S, Foccoli P, Toninelli C, Feijo S. Nd:YAG laser therapy in lung cancer: An 11-year experience with 2,253 applications in 1,585 patients. J Bronchol 1994; 1: 105-111.

176. Mathur PN, Wolf KM, Busk MF, Briete WM, Datzman M. Fiberoptic bronchoscopic cryotherapy in the management of tracheobronchial obstruction. Chest 1996; 110: 718-723.

177. Sutedja G, van Boxem TJ, Schramel FM, v Felius C, Postmus PE. Endobronchial electrocautery is an excellent alternative for $\mathrm{Nd}: \mathrm{YAG}$ laser to treat airway tumors. J Bronchol 1997; 4: 101-105.

178. McCaughan JS, Williams TE. Photodynamic therapy for endobronchial malignant disease: A prospective fourteen-year study. J Thorac Cardiovasc Surg 1997; 114: 940-947.

179. Huber RM, Fischer R, Hautmann H, Pollinger B, Haussinger $\mathrm{K}$, Wendt $\mathrm{T}$. Does additional brachytherapy improve the effect of external irradiation? A prospective, randomized study in central lung tumors. Int J Radiat Oncol Biol Phys 1997; 38: 533540 .

180. Cohen MD, Weber TR, Rao CC. Balloon dilatation of tracheal and bronchial stenosis. AJR Am J Roentgenology 1984; 142: 477-478.

181. Liermann D, Becker HD, Rust M. Endoprostheses in the tracheobronchial system. In: Adam A, Dondelinger R, Mueller PR, eds. Textbook of metallic stents. Oxford, Isis Medical Media, 1997; pp. $129-142$

182. Rafanan AL, Mehta AC. Stenting of the tracheobronchial tree. Radiol Clin N Am 2000; 38: 395-408.

183. Bolliger CT, Probst R, Tschopp K, Soler M, Perruchoud AP. Silicone stents in the management of inoperable tracheobronchial stenoses. Indications and limitations. Chest 1993; 104: 1653-1659.

184. Petrou M, Goldstraw P. The management of tracheobronchial obstruction. A review of endoscopic techniques. Eur J Cardiothorac Surg 1994; 8: 436-441. 
185. Becker HD. Stenting the central airways. J Bronchol 1995; 2: 98-106.

186. Dumon JF, Cavaliere S, Diaz-Jimenez JP, et al. Sevenyear experience with the Dumon prosthesis. J Bronchol 1996; 3: 6-10.

187. Wilson GE, Walshaw MJ, Hind CR. Treatment of large airway obstruction in lung cancer using expandable metal stents inserted under direct vision via the fiberoptic bronchoscope (see comments). Thorax 1996; 51: 248-252.

188. Freitag L, Tekolf E, Stamatis G, Greschuchna D. Clinical evaluation of a new bifurcated dynamic airway stent. A five year experience in 135 patients. Thorac Cardiovasc Surg 1997; 45: 6-12.

189. Nicholson DA. Tracheal and oesophageal stenting for carcinoma of the upper oesophagus invading the tracheo-bronchial tree. Clin Radiol 1998; 53: 760-763.

190. Freitag L. Tracheobronchial stents. In: Bolliger CT, Mathur PN, eds. Interventional bronchoscopy. Respiratory Research, vol. 30. Basel, Karger, 1999; Vol. 30, pp.171-186.

191. Freitag L, Tekolf E, Steveling H, Donovan TJ, Stamatis G. Management of malignant esophagotracheal fistulas with airway stenting and double stenting. Chest 1996; 110: 1155-1160.

192. Sawada S, Fujiwara Y, Furui S, et al. Treatment of tuberculous bronchial stenosis with explandable metallic stents. Acta Radiol 1993; 34: 263-265.

193. Rousseau H, Dahan M, Lauque D, et al. Selfexpandable prostheses in the tracheobronchial tree. Radiology 1993; 188: 199-203.

194. Strausz J. Management of postintubation tracheal stenosis with stent implantation. J Bronchol 1997; 4: 294-296.

195. Dechambre S, Dorzee J, Fastrez J. Bronchial stenosis and sclerosing mediastinitis: An uncommon complication of external thoracic radiotherapy. Eur Respir $J$ 1998; 11: 1188-1190.

196. Filler RM, Forte V, Chait P. Tracheobronchial stenting for the treatment of airway obstruction. Pediatr Surg 1998; 33: 304-311.

197. Nakajima Y, Kurihara Y, Niimi H, et al. Efficacy and complications of the Gianturco-Z tracheobronchial stent for malignant airway stenosis. Cardiovasc Intervent Radiol 1999; 22: 287-292.

198. Hautmann H, Bauer M, Pfeifer KJ, Huber RM. Flexible bronchoscopy: A safe method for metal stent implantation in bronchial disease. Ann Thorac Surg 2000; 69: 398-401.

199. Nordenstrom BE. Fleischner lecture. Biokinetic impacts on structure and imaging of the lung: the concept of biologically closed electric circuits. AJR Am J Roentgentology 1985; 145: 447-467.

200. Brach B, Buhler C, Hayman MH, Joyner LR, Liprie SF. Percutaneous computed tomography-guided fine needle brachytherapy of pulmonary malignancies. Chest 1994; 106: 268-274.

201. Dupuy DE, Zagoria RJ, Akerley W, Mayo-Smith WW, Kavanagh PV, Safran H. Percutaneous radiofrequency ablation of malignancies in the lung. AJR Am J Roentgenology 2000; 174: 57-59.

202. Korpela A, Aarnio P, Sariola H, Tormala P, Harjula A. Bioabsorbable self-reinforced poly-L-lactide, metallic and silicone stents in the management of experimental tracheal stenosis. Chest 1999; 115: 490-495. 